
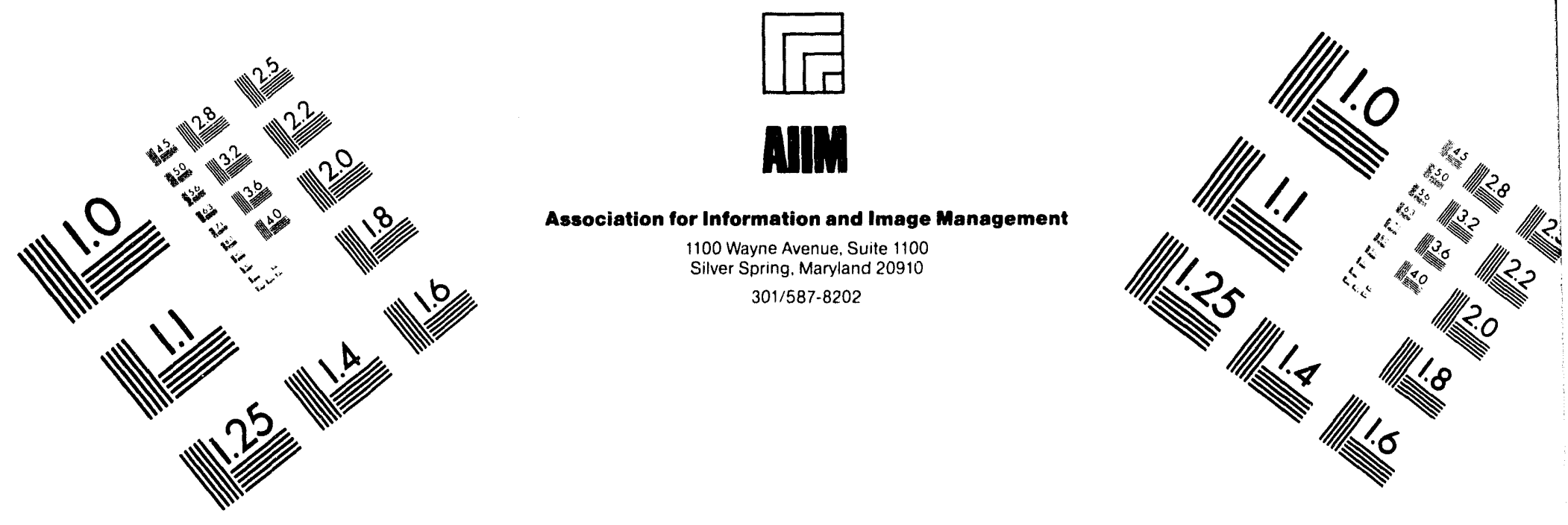

\title{
Centimeter
}

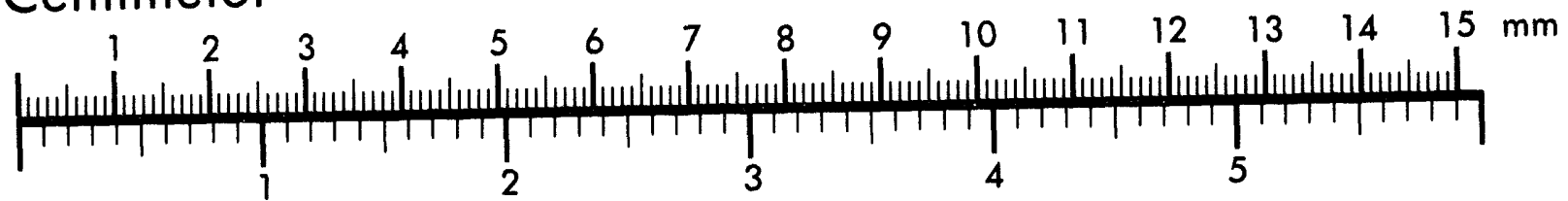

Inches
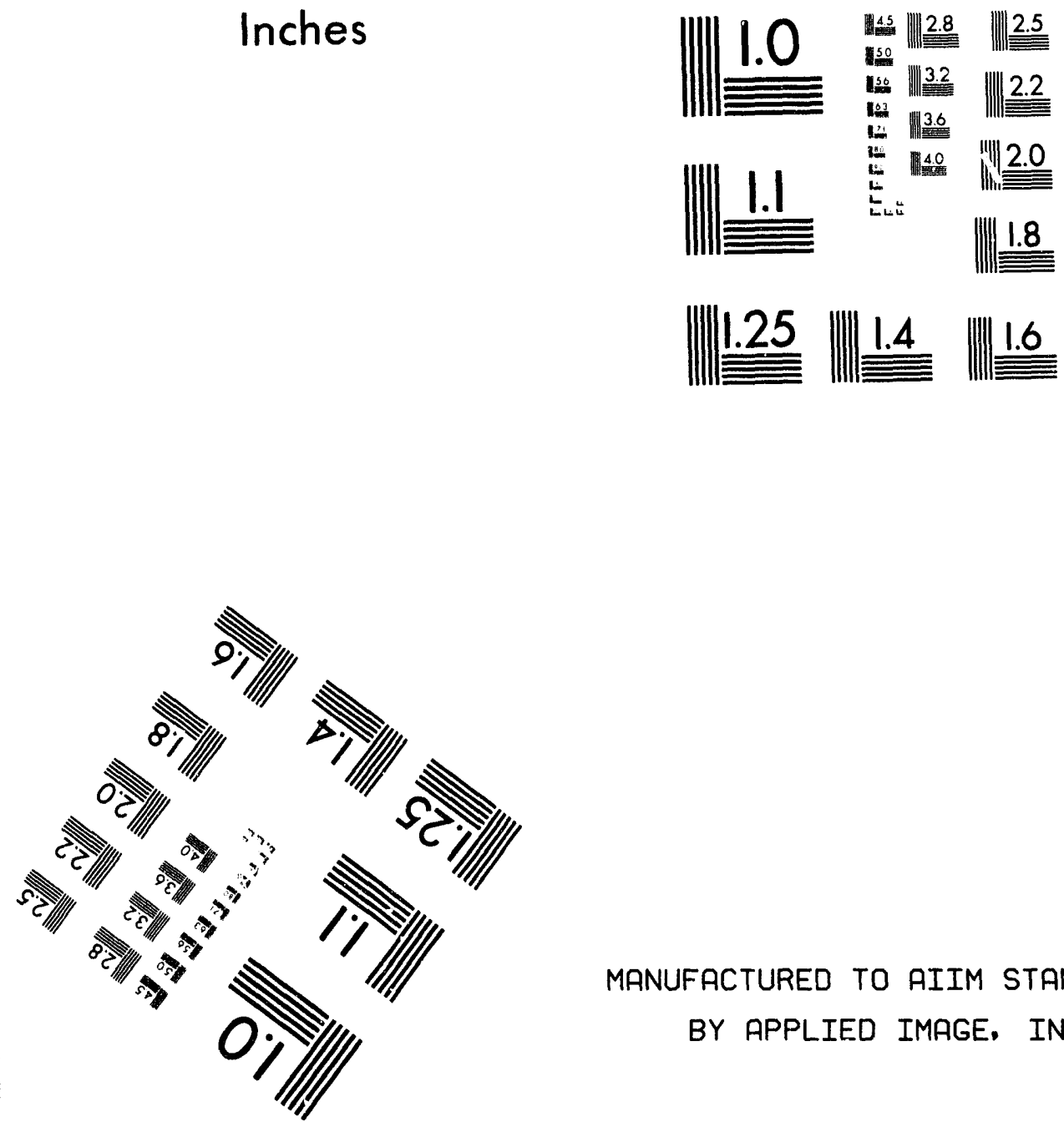

MANUFACTURED TO AIIM STANDARDS

BY APPLIED IMAGE, INC.

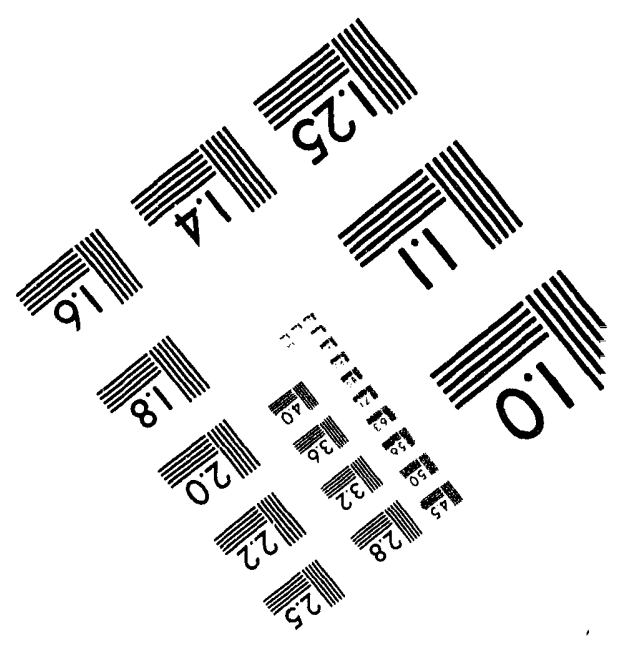



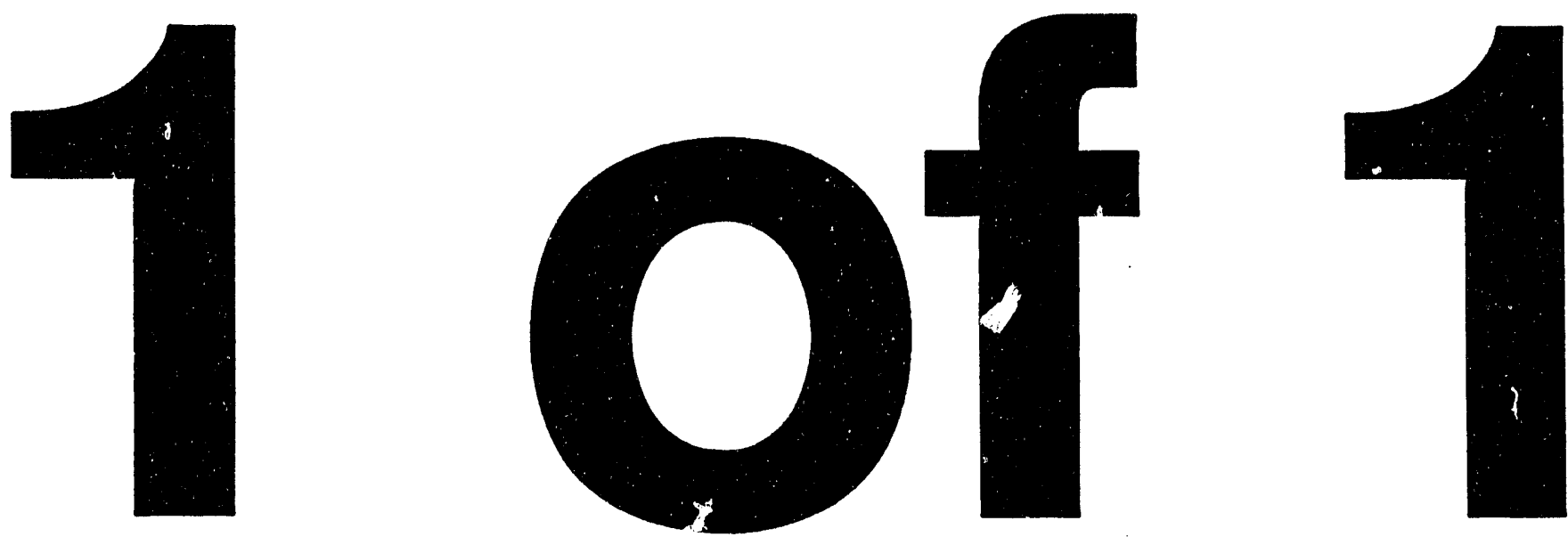


\section{ENVIRONMENTAL AND HEALTH ASPECTS OF LIGHTING: MERCURY}

Robert Clear and Sam Berman

Lighting Research Group

Energy and Environment Division

Lawrence Berkeley Laboratory

Berkeley, California 94720

\section{July 1993}

\section{Acknowledgement}

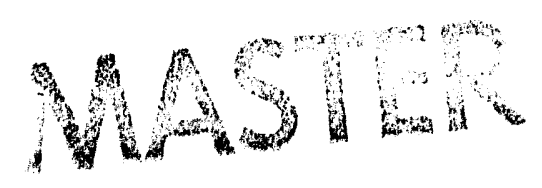

This work was supported by the Assistant Secretary for Energy Efficiency and Renewable Energy, Office of Building Technologies, Building Equipment Division of the U.S. Department of Energy undier Contract No. DE-ACO3-76SFO0O98. 


\title{
ENVIRONMENTAL AND HEALTH ASPECTS OF LIGHTING: MERCURY
}

\author{
Robert Clear and Sam Berman \\ Lighting Research Group \\ Energy \& Environment Division \\ Lawrence Berkeley Laboratory \\ Berkeley, California 94720
}

\begin{abstract}
Most discharge lamps, including fluorescent lamps, metal halide lamps, and high pressure sodium lamps, contain Mercury, a toxic chemical. Lighting professionals need to be able to respond to questions about the direct hazards of Mercury from accidentally breaking lamps, and the potential environmental hazards of lamp operation and disposal.

We calculated the exposures that could occur from an accidental breakage of lamps. Acute poisoning appears almost impossible. Under some circumstances a sealed environment, such as a space station, could be contaminated enough to make it unhealthy for lono-term occupation.

Mercury becomes a potential environmental hazard after it becomes methylated. Mercury is methylated in aquatic environments, where it may accumulate in fish, eventually rendering them toxic to people and other animals. Lighting causes Mercury to enter the environment directly from lamp disposal, and indirectly from power plant emissions. The environmental tradeoffs between incandescent and discharge lamps depend upon the amounts released by these two sources, their local concentrations, and their probabilities of being methylated. Indirect environmental effects of lighting also include the release of other heavy metals (Cadmium, Lead and Arsenic), and other air pollutants and carbon dioxide that are emitted by fossil fuel power plants. For a given light output, the level of power plant emissions depends upon the efficacy of the light source, and is thus much larger for incandescent lamps than for fluorescent or discharge lamps. As disposal and control technologies change the relative direct and indirect emissions from discharge and incandescent lamps will change.
\end{abstract}

\section{Introduction}

Mercury is a well known toxin. In recent years questions have arisen as to whether the small quantities found in some lamps might be hazardous. Currently two states treat lamps as hazardous wastes, and many more are considering it. This paper covers two questions: do mercury containing lamps pose a direct hazard when they are broken, and are they worse for the environment than. incandescent lamps?

Mercury has been used industrially for a long time, and most of the literature on its direct health effects are from studies of miners and other industrial workers. There are large differences in individual sensitivities to mercury. We evaluated the toxic risk of accidental lamp breakage by comparing the mercury levels found in the above studies for sensitive individuals with estimates of the levels likely to be found after lamp breakage. There is little chance of poisoning from accidental fluorescent lamp breakage. There is a small risk from HIDs in confined, poorly ventilated spaces. Abnormal circumstances, such as fire, or explosion, or the associated cleanup, could possibly create a poison hazard with fluorescent lamps. 
An awareness of the environmental risks of mercury is more recent than the knowledge of its direct health effects. After mercury escapes iito the environment some fraction of it is converted to methylmercury. It is methylmercury that causes most environmental problems, not elemental mercury per se. The reason for this is that elemental mercury tends to disperse in the environment, while methylmercury, which is formed from mercury in aquatic environments, is concentrated by fish. Methylmercury contaminated fish were responsible for several hundred deaths and extensive misery in Minamata, Japan.

Mercury is an element, and as such is naturally present in the environment. Most of this mercury is locked up in rock or soil in forms that are not accessible to the biota of the world. At issue is the mersury that is "bioavailable". Recent studies indicate that the anthropogenic input to the mercury cycle is much more important than was previously believed. Problems with mercury in the environment have become more evident too, and there is considerable effort now being devoted to reducing the amount of mercury mobilized by man.

The issue with regards to lamps is complicated by the fact that fossil fuels contain mercury. Depending upon the fuel, and the technology used for pollution control, more mercury can be released generating electricity during the operation of a lamp than at the lamp's ultimate disposal. There are many uncertainties as to how much mercury from power generation and lamp disposal ends up as methylmercury, but switching from fluorescent lamps to incandescents is not likely to reduce environmental hazards, and switching to long-life incandescents is clearly counter-productive.

Much of the material discussed is far removed from normal lighting issues. The reader who is only interested in the conclusions is invited to skim the text, and concentrate on the figures and tables.

\section{Acute Hazards}

\section{Backaround 1: Mercun Toxicity}

Elemental mercury is a silvery metal that is liquid at room temperatures. The metal is not toxic on ingestion, although large doses may cause diarrhea. It is estimated that less than 0.01 percent of ingested metal is absorbed. Similarly absorption through the skin appears low. All cases of metal mercury poisoning that we located were due to inhalation of the vapor, either by itself or in conjunction with fine particulates. Absorption of the vapor through the lungs has been estimated as being about 80 percent.

Elemental mercury diffuses into the blood from the lungs, and then diffuses into tissue. It readily passes through the blood-brain barrier. Within the blood and, to a lesser extent, other tissues as well, such as the brain, elemental mercury, $\mathrm{Hg}^{\circ}$, is oxidized to mercuric ion, $\mathrm{Hg}^{+2}$. The ion binds strongly with sulfur in proteins and enzymes, disrupting their function. At high concentrations the ion denatures protein. It is presumably the ion that at high vapor concentrations causes an inflammation in the lung (mercury pneumonitis). A five hour exposure while cleaning up several tons of hot mercury from a broken boiler, gave all eight workers pneumonitis, and ultimately resulted in one death. Similar symptoms were found in four men cleaning up a mercury storage tank, a farnily that attempted to refine gold with mercury on the stove, and a family that painted a radiator with a paint containing $60 \%$ mercury by volume. In the last case the children died, and in general children are thought to be more susceptible to mercury toxicity than adults. In the case of the father who attempted to refine gold (it was unfortunately just pyrite!) a follow-up showed that he still had difficulty in breathing (dyspnea) during exercise a year later. 
At lower mercury concentrations, acute symptoms, such as lung damage, are no longer seen. In chronic exposures, mercury accumulates until an equilibrium is struck between the mercury inhaled and mercury excreted. Mercury excretion is slow, and it takes almost 60 days for the body burden to drop by half after cessation of exposure.

Before the imposition of controls, it was not uncommon for industrial workers chronically exposed to high concentrations of mercury to show symptoms of kidney damage, brain and neurological damage such as tremor and personality disorders (including a tendency towards suicide), and finally lesions to the mouth and gums. Less severe poisoning due to lower exposure levels, or an individuals' lower sensitivity to mercury, is generally seen as mild tremor, irritability, disturbed sleep and other mild symptoms of brain or neurological damage. Approximately one out of every thousand children has a sensitivity to mercury, and develops a disorder called acrodynia upon exposure to moderate concentrations of it. Acrodynia is characterized by rash, anorexia, pain in the extremities, and irritability. There is some suspicion that acrodynia is an auto-immune reaction. It is also thought that Kawasaki's disease, which is characterized by swollen lymph nodes, rash, and fever, may be caused by mercury. At even lower exposure levels at least one study claims an apparent increase in the size of the thyroid in a small fraction of exposed individuals.

Terminating an individual's exposure to mercury is generally sufficient to eliminate the above symptoms after several months in all but the most severely poisoned individuals. In these later individuals there is a possibility of some permanent neurological damage.

Figure 1 shows the estimated exposure levels that were responsible for the various degrees of poisoning that are described above. It should be noted that the estimates of the actual exposure levels have large uncertainties as they are often derived from reconstructions after poisoning events. For comparison and later reference it also shows background mercury levels. From the figure, a potentially acute (but non-fatal) toxic level can be taken to be $3 \mathrm{mg} / \mathrm{m}^{3}$, over a period of 4 hours. This should be a conservative estimate as there have been a number of cases with exposures at or slightly above this level without any acute symptoms.

\section{Mercury In Lamps}

Until recently the amount of mercury in discharge lamps was determined by operational and economic factors. During operation of the lamp chemical reactions with filament material, and possibly losses to other lamp components as well, slowly make much of the mercury in a lamp unavailable. Lamps are filled with enough mercury that these losses do not limit lamp life. During operation of an F40 lamp at $40^{\circ} \mathrm{C}$, only 0.1 to 0.3 percent of the total lamp mercury is in the vapor form, while in compact fluorescents the percentage is 0.01 to 0.07 percent.

Some lamps made on older equipment will have just enough mercury to last over their lifetime, while other lamps will have much more than enough. This makes the average amount of mercury higher than it needs to be. Some new types of modern equipment are more precise, and the average amount of mercury in lamps made on them is $1 / 2$ or less of that of lamps made on old equipment. The variability of the fill on modern equipment appears to still be about $40 \%$ of the average fill. Thus potentially the average could be reduced by another third, while still maintaining the minimum fill level.

Lamp equipment may handle a variety of lamp types, and the amount of mercury dispensed has to be sufficient for the largest lamps made on the equipment. Management at the two companies that we contacted noted that all their normal output compact twin-tube lamps had the same fill of mercury, regardless of wattage. Higher output compact quad lamps were made on different machines, and had a slightly higher fill of mercury. 
Manufacturers are buying more new machines, and retooling old ones, and the amount of mercury per lamp is shrinking. Table 1 lists estimates of the mercury loading culled from a variety of sources.

All of the mercury in Mercury and Metal Halide HID lamps is in the vapor form during operation of the lamp. High pressure sodium (HPS) lamps contain a $\mathrm{Hg}-\mathrm{Na}$ amalgam. Excess. amalgam is used to control pressure and to allow for sodium loss. Calculations suggest that roughly 50 percent of the initial $\mathrm{Hg}$ dose in typical HPS lamps is in the vapor phase during operation. HPS lamps can be made without mercury, but only at the cost of a loss in performance.

Table 1 shows estimates for mercury loading for some of these lamps. The watts $/ \mathrm{mg} \mathrm{Hg}$, and lumens $/ \mathrm{mg} \mathrm{Hg}$ columns of this table allow comparisons between different lamps. Mercury and metal halide lamps average $0.18 \mathrm{mg} \mathrm{Hg}$ per watt.

A 175 watt metal halide with $30 \mathrm{mg}$ of mercury can potentially contaminate a 10 cubic meter enclosure to the $3 \mathrm{mg} / \mathrm{m}^{3}$ acute hazard level. A set of 4 older F40 fluorescent lamps could potentially contaminate a 67 cubic meter enclosure. Ventilation will reduce the amount of time a room is contaminated. Most of the mercury in a fluorescent lamp is not in the vapor phase during operation, so the actual volume that is seriously contaminated also depends on how fast the mercury evaporates. The next section develops formulas for the rate of evaporation as a function of the temperature, the mass of the mercury, and the number of drops.

\section{Evaporation Rates}

When a fluorescent lamp breaks most of the mercury in the lamp is in liquid form, and the concentration of the mercury in air depends upon the relative amounts of liquid and vapor, and how long the liquid takes to evaporate. We have assumed that the mercury in the lamp is at equilibrium (saturation) pressure. A fit of the vapor pressure, $\mathbf{P}$, of mercury in torr, as a function of temperature, $\mathrm{T}$ (in ${ }^{\circ} \mathrm{K},{ }^{\circ} \mathrm{K}=273.16+{ }^{\circ} \mathrm{C}$ ) is given by the formula:

$$
P=1.3366 \times 10^{8} \times e^{-7457.2 / T}
$$

An estimate of the gas density, $\rho,(\rho=n M / V)$ in $n g ~ H g / m^{3}$, can be obtained from equation 1 , the ideal gas law (PV $=n R T)$, and the atomic weight of mercury $(M=200.59 \mathrm{grams} / \mathrm{mole})$ :

$$
\rho=\left(4.302 \times 10^{20} \times e^{-7457.2 / T}\right) / T
$$

A theoretical estimate of the rate of evaporation of mercury can be made by combining the kinetic theory of gases and the theory of diffusion. The kinetic gas theory states that the mass of atoms evaporating from a surface, $G$, is less than or equal to the mass striking the surface when liquid (or solid) and gas are in equilibrium:

$$
G=A P_{s}(M / 2 \pi R T)^{1 / 2}=A \rho_{s}(R T / 2 \pi M)^{1 / 2}=2.57 \times 10^{-4} A \rho_{s} T^{1 / 2}
$$

where $G$ is in units of grams $/ \mathrm{sec}, \rho_{s}$, the saturation vapor density is in units of $\mathrm{grams} / \mathrm{m}^{3}, A$, the area is in units of $\mathrm{cm}^{2}, M$ is the atomic weight as before, and $R$ is the gas constant $\left(8.31432 \times 10^{7}\right)$. The net evaporation rate is reduced by condensation and is $G\left(1-\rho_{\mathrm{f}} / \rho_{\mathrm{s}}\right)$, where $\rho_{f}$ is the density of the vapor in a thin film immediately adjacent to the liquid.

In a surface under air the evaporating vapor has to diffuse from the vicinity of the surface. Mercury beads into a hemispherical shape. The area and radius of a mass of mercury, $m$, is 
related to the density of liquid mercury, $\rho_{1}=13.546 \mathrm{~g} / \mathrm{cc}$, and the number of droplets, $\mathrm{n}$, by the equations:

$$
\begin{aligned}
& A=\left(18 \pi \mathrm{m}^{2} \mathrm{n} / \rho_{1}^{2}\right)^{1 / 3}=0.6755\left(\mathrm{~m}^{2} \mathrm{n}\right)^{1 / 3}\left(\mathrm{~cm}^{2}\right) \\
& r=\left(3 \mathrm{~m} / 2 \pi n \rho_{1}\right)^{1 / 3}=0.3279(\mathrm{~m} / \mathrm{n})^{1 / 3}(\mathrm{~cm})
\end{aligned}
$$

Diffusion, $D$, from $\mathbf{n}$ half spheres is:

$$
D=D_{0}\left(T / T_{0}\right)^{N} A\left(\rho_{f}-\rho_{r}\right) / r
$$

here $D_{0}$ is the measured diffusion coefficient $\left(\mathrm{cm}^{2} / \mathrm{sec}\right)$ at temperature $T_{0}$. The exponent $N$ is a constant in the range from 1.5 to 2, $A$ is the area, and $r$ is the radius of the droplets, and finally $\rho_{r}$ is the vapor density in the room as a whole. Jost gives values for the diffusion coefficient, $D_{0}$, of mercury in air that average to 0.13 at $0{ }^{\circ} \mathrm{C}$. No values were found for the exponent $N$, and we therefore use the value $N=1.75$.

After a short time the rates of net evaporation and diffusion Decome the same. Setting G(1$\rho_{f}\left(\rho_{s}\right)$ and $D$ equal eliminates the unknown vapor density term, and gives an equation for the evaporation rate, E, of mercury drops in $\mathrm{mg} / \mathrm{hr}$ as a function of temperature in ${ }^{\circ} \mathrm{K}$, the mass of the mercury in grams, and the number of drops:

$$
\begin{aligned}
E & =D\left(T / T_{0}\right)^{N} A\left(\rho_{s}-\rho_{r}\right) /\left[r+D\left(T / T_{0}\right)^{N}(2 \pi M / R T)^{1 / 2}\right] \\
& =5.25 \times 10^{-8}\left(n^{2} \mathrm{~m}\right)^{1 / 3} T^{1.75}\left(\rho_{s}-\rho_{r}\right) /\left[1+8.4 \times 10^{-8} T^{1.25}(n / m)^{1 / 3}\right] \\
& =R\left(\rho_{s}-\rho_{r}\right)
\end{aligned}
$$

Here $R$ has units of $m^{3} / \mathrm{hr}$, while $\rho_{s}$ and $\rho_{r}$ have units of $\mathrm{mg} / \mathrm{m}^{3}$.

This theoretical estimate gives the evaporation in still air for a clean unoxidized surface. Rapid air motion over the liquid surface speeds diffusion, and hence evaporation, but is likely to also clear the vapor from the room or immediate vicinity of the liquid. A dirty or oxidized surface can vastly reduce the area of evaporation, and thus slow it. To better determine the actual rates that might be expected we put a small sample of mercury in a flat dish, and weighed the dish, and two empty control dishes, several times over a period of days. While evaporation averaged over the first two hours appears to have been at about the rate predicted by equation 7 , more precise measurements over the several days following were only 0.2 times as fast as predicted. Because of turbulence the evaporation rate was probably initially higher than diffusion limited rate predicted by equation 7. For calculation convenience we have assumed that evaporation falls exponentially to its asymptotic rate of 0.2 times the theoretical rate during the first two hours. The average rate over the first two hours was set equal to the diffusion rate. The calculations in the next section are not sensitive to the details of this assumption.

\section{Is There an Acute Poisoning Hazard with Lamos?}

Figure 2 shows the calculated concentration of mercury in air for six different lamp breakage scenarios. The lowest mercury level in the figure $\left(0.01 \mu \mathrm{g} / \mathrm{m}^{3}\right)$ is the assumed background level for the area. The $100 \mu \mathrm{g} / \mathrm{m}^{3}$ and $3,000 \mu \mathrm{g} / \mathrm{m}^{3}$ levels are identified with arrows as being respectively the levels for acrodynia in chronic exposures, and the level that may have 
resulted in acute poisoning of workers cleaning a mercury storage tank. Two of the scenarios in figure 2 involve a 175 watt metal halide lamp (HID) with $30 \mathrm{mg}$ of mercury. The remaining four scenarios assume four F40 fluorescent lamps with $50 \mathrm{mg}$ mercury each. The scenarios are based on an approximately 500 lux initial design level in a 2.5 meter high room, with 10 square meters surface area. The lamps are operating, and all the initial vapor is released into the room. In the three scenarios labeled "Confined" it is assumed that an earthquake causes the ceiling to fall, and all the mercury, and the victim, are confined to a 5 cubic meter volume. It is further assumed that after the collapse the air is very still, and mixes with outside air at a rate of 0.2 air changes per hour. In the normal cases it is assumed that there is 0.5 air changes per hour, and that the room volume remains 25 cubic meters. The numbers 40 and $\mathbf{4 0 0}$ refer to the number of drops of mercury that are assumed to result from the lamp breakage. After accidents in our laboratory, laboratory personnel claim that they find approximately 10 drops of mercury. The range 40 to 400 is meant to cover the likely range for four broken fluorescent lamps. The air temperature in all scenarios is assumed to be $25^{\circ} \mathrm{C}\left(77^{\circ} \mathrm{F}\right)$, as higher temperatures lead to higher evaporation rates.

All the mercury in the operating metal halide lamps is released in the vapor form. For the two metal halide scenarios the concentration of mercury in air follows an exponential decay with the time constant given by the air change rate. In the four fluorescent lamp scenarios only about 1/5 percent of the mercury is initially released into the air as vapor. We are assuming that the lamps are new, so that the remaining mercury is in the liquid form at the coldspot.

The evaporation rate (equation 7) depends upon the mass of the mercury in a moderately complicated fashion. An approximate closed-form solution for the concentration of mercury in the air is available if the time period, $t$, is limited to a period short enough that the evaporation rate is essentially constant:

$$
\rho_{r}(t)=\rho_{r i} e^{-B t}+R \rho_{s}\left(1-e^{-B t}\right) / V B
$$

Here $\rho_{r i}$ is the initial concentration of mercury, $R$ is the evaporation rate from equation 7 , and $B$ is a time constant equal to the air change time constant, $a$, and an evaporation rate time constant, $R / V(B=a+R / V)$, where $V$ is simply the room volume. The curves in figure 2 were calculated from equation 8 , with $R$ updated at each calculation point.

Figure 2 shows that breaking an operating HID in a confined, poorly ventilated space, could lead to acute poisoning of sensitive individuals. Mercury concentrations in the fluorescent lamp scenarios are not acutely toxic, but in a confined, poorly ventilated space they might cause acrodynia in sensitive children if the exposures last several months. To reach this hazard levels in a normal environment one has to assume a scenario like breaking a carton (24) of lamps during relamping onto a carpet where the mercury is squished around into lots of little droplets and never cleaned up. Poisoning of adults would require even more extreme conditions, such as a fire, or the coincidental breakage of other mercury containing devices, such as thermostats or thermometers, which could drastically increase the amount of mercury in the air.

\section{Mercury in the Environment}

What is the Hazard?

Mercury vapor is an occupational hazard, but it is not a direct environinental hazard. Mercury vapor released into the atmosphere is diluted by diffusion and advection, and scavenged from the atmosphere by surface reactions and settling. Scavenging prevents mercury from continually building up in the atmosphere, while diffusion and advection prevent excessive 
local buildups. The equilibrium atmospheric concentration is proportional to the ratio of mercury releases and the "residence" time for mercury in the atmosphere. Atmospheric residence times for mercury vapor are usually on the order of months, so equilibrium is obtained in few years.

Figure 1 shows that a large urban area, such as Chicago, may have an ambient concentration ten times that of a rural area. General ambient air near mines can reach 100 times the general background level, while localized areas sometimes reach 1,000 to 10,000 times the background level. The lower levels are well below the levels where any health effects have been reported, while the highest levels are transitory and are thus still not likely to cause health effects.

Mercury scavenged from the atmosphere is usually oxidized to $\mathrm{Hg}^{+2}$, which then binds to clays, soils or organic matter, or can be dissolved into water as an ion, or as an ionic complexe, or compound. Some mercury eventually re-evaporates. Some cycles between land and water, and some eventually settles out in sediments which are buried and effectively removed from circulation.

Mercury on land has not been a serious problem. Mushrooms and carrots concentrate mercury by factors of 10 to 30 , but most plants do not concentrate it, and many actually have lower mercury concentrations than the soil in which they are grown. The mercury in plants is primarily inorganic mercury, which is inefficiently absorbed on ingestion. Recently it has been suggested that earthworms can concentrate mercury from the soil, but as yet there have been no reports of any problems arising from this source.

The problem with contaminated land a.d air is that they in turn can contaminate water. Aquatic organisms are at risk both from inorganic mercury and methylmercury ions $\left(\mathrm{Hg}^{++}\right.$and $\mathrm{CH}_{3} \mathrm{Hg}^{+}$). Methylmercury is generally considered to be more toxic to aquatic organisms than inorganic mercury, although the measured differences in toxicity are sometimes very small. Methylmercury is concentrated by fish and is thus hazardous to land animals that eat fish, including man, as well as aquatic ones.

Mercury appears to be methylated primarily by microbiological activity in sediments, and then mixes into the water column. Methylmercury constitutes less than 1 to 20 percent of total mercury in water, and from 0.1 to 1.5 percent of total mercury in sediments. The fraction depends on its rate of formation, and its rate of removal from microbial demethylization reactions, further methylization to dimethylmercury, which is volatile, and removal by fish and other aquatic organisms.

Concentrations of mercury in the tissue of the fish have been reported from 100,000 to $1,000,000$ times the concentration of total mercury in the water. Fish have a fairly high tolerance for methylmercury, and measured concentrations reach up to $3 \mathrm{c} . \mathrm{ppm}$. These high concentrations are a hazard to animals that prey on fish. Unlike elemental mercury, methylmercury is readily absorbed after ingestion. In man it is estimated that 95 percent or more of an ingested dose is absorbed, and many other animals may be equally efficient.

Methylmercury has been implicated in the deaths of loons and the Florida panther, and seems to be serious:ly affecting mink, otter, and raccoons. In the late 1950 s and early 1960s, severely contaminated water in Minamata Bay, Japan, killed hundreds of people, and left thousands more permanently disabled. Currently, in the U.S. there are fish advisories because of methylmercury in 26 states, and there are similar problems in Canada and Sweden. In Canada, Cree Indians are suffering from what they call "nimass aksiwin", or fish disease. 
The environmental mercury hazard from discharge lighting can be evaluated in terms of the factors that affect methylmercury exposure:

1) The amount of mercury in discharge lamps

2) The number of discharge lamps being disposed

3) The amount of mercury in fossil fuels

4) The fraction of power generated by different fuels

5 ) The efficiencies of discharge and incandescent lamps

6) The fraction of released mercury that reaches water

7) The size and salinity of the body of water that receives mercury

8 ) The magnitude of other natural and anthropogenic fluxes of mercury to the body of water

9) The rate at which mercury is removed from a body of water

10) The efficiency of conversion of inorganic mercury in water to methylmercury including synergistic or antagonistic effects from other emitted compounds

11) Exposure of different organisms to methylmercury

12) The toxicity of methylmercury

We present a brief discussion of the toxicity of methylmercury and then discuss the factors affecting the relative risks of fluorescent and incandescent lamps. It is important to note that our comparison only covers mercury. Power plants emit lead, arsenic, cadmium, selenium, and a number of other trace metals, plus a number of environmentally hazardous combustinn products, that have to be considered in an overall comparison.

\section{Inorganic and Methylmercury Toxicity}

The mode of toxic action of methylmercury is similar to that of inorganic mercury ion, but there are important differences. Methylmercury is lipid soluble, and as a consequence is more uniformly distributed in the body than $\mathrm{Hg}^{+2}$. Methylmercury readily penetrates the bloodbrain barrier, and is found in high concentrations in the brain. Inorganic mercury ion primarily attacks the kidneys, while neurological effects are much more pronounced in methylmercury poisoning. Mild methylmercury poisoning results in abnormal spontaneous sensations such as prickling, or numbness (paresthesia), nualaise, and blurred vision. More severe cases result in irreversible tunnel vision, deafness, a type of difficulty in speech (dysarthria), loss of coordination (ataxia), mental derangement, coma, and finally death. Both forms of mercury readily pass through the placenta, and are found in mother's milk. Methylmercury disrupts normal neuronal development and can result in severe irreversible brain damage in infants exposed to it prenatally. Damage to infants can occur at exposure levels which are not sufficient to cause symptoms in adults.

For methylmercury the time needed for the body burden to drop to half its initial level after cessation of exposure is about 70 days. It is primarily eliminated by excretion with bile into 
the gut, where some of it is demethylated. Only 7 to 30 percent of the resultant inorganic mercury is reabsorbed, and the rest is excreted with the feces. Inorganic mercury is less toxic than methylmercury because of its relatively poor absorptivity in the gut, and its relative inability to attack the brain.

Figure 3 lists total mercury levels in water, along with estimated toxic levels. The abbreviation LD50 in this figure indicates the dose which is lethal to 50 percent of the target population. Only a limited amount of concentration data was found, as much of the pre-1985 data is suspect. One recent study found that stringent protocols to control contamination gave measurements in the parts per trillion range, while earlier measurements of the same areas were typically one thousand times higher. Early values in the parts per billion and above range are less suspect because contamination is less of a problem. Fish biomagnification estimates are directly affected by these errors, with the result that early estimates were often in the range of 1,000 to 10,000 , while the more modern estimates range up to a million. These early estimates are sometimes still quoted.

The figure shows that polluted run-off from sewage or mines can produce levels that can produce stress or death in sensitive organisms, particularly in freshwater systems. Total mercury tends to be more concentrated in sediments than water, but is less accessible. Sediments are generally considered to be a sink for mercury, although they can become a source if disturbed. The highest sediment levels recorded, 2,000 parts per million in Minimata Bay, Japan, were too high to indicate on the figure.

The toxic levels listed in figure 3 for human beings assume an adult water consumption of 2 liters per day, with ten percent of the mercury being methylmercury. The Australian recommended drinking water standard was based on the assumption that all the mercury is methylmercury, and that an individuals total mercury exposure is ten times the exposure from drinking water. The standard was further set a level ten times below the level known to cause problems in adults. The potential fish contamination level assumes that fish concentrate mercury by a factor of 100,000 . It is described more fully with the discussion of figure 4 . The inorganic mercury hazard level was derived from studies on rats. The methylmercury dose estimates were based on a tragic incident of organic mercury poisoning in Iraq in 1972. In this incident, seed grain coated with organic mercury was baked into bread. All of the calculations assume that exposure lasts for one year, so that the amount of mercury in the body has stabilized. Body burden estimates from this accident were divided by the decay constant for mercury in the body to give the daily dose that will give the body dose. As can be seen from the figure, drinking water is not presently a direct toxic risk to people, but food contamination is.

Figure 4 lists the concentrations of mercury in food. Calculations of possible toxic levels are based on an adult food intake of $1.5 \mathrm{~kg}$ per day. For a no fish diet one can assume that all of the mercury is inorganic mercury, and that only 7 percent of its is absorbed from the gut. The average amount of fish consumed in the U.S. is 18.7 grams per day. For comparison, the Cree Indians in Ontario are reported to eat as much as $1.3 \mathrm{~kg}$ of fish per day during the summer months. Over a year this gives approximately twenty times the average exposure level. The two lowest hazard levels are shown for both the average fish diet and for twenty times the average fish diet. All the fish diet calculations assume that fish mercury is 80 percent methylmercury, and that all the methylmercury is absorbed. The figure shows that contaminated fish are a toxic hazard to man. Other fish eating animals are even more at risk.

Mercury from Power Production

Figure 5 shows the relative contributions over the last twenty years of the five major sources for electric power in the United States. Nuclear power has captured an increasing share of 
power generation, but fossil fuels are still the dominant source of U. S. electricity. The fossil fuel fraction may even increase, because new nuclear power plant construction is currently at a standstill.

Far more mercury is released during the combustion of coal than from nuclear-electric generation, so the answer to the question of whether an incandescent or fluorescent lamp releases more is site specific. It is beyond the scope of this paper to do a place by place analysis of power plant emissions. We have instead attempted to gather information on the ranges and mean values of mercury in fuels, plus information on the factors, such as control technologies, which affect actual power plant emissions.

The amount of mercury in a given fuel depends upon its source, and varies over a wide range. For U. S. coals the reported range is $1,000: 1$, for crude oils the reported range is $5,000: 1$, for gas and European coal the range may be as high as $250,000: 1$. The extreme values of these ranges are very uncommon. Figure 6 shows a smoothed plot of the probability distribution for the mercury concentration for bituminous coal in the U.S., which is the most common form of coal in the U. S.. The distribution is very skewed, with the bulk of most coals clustered over a narrow concentration range, and then a long low probability tail out to high concentrations. The low probabilities of the high concentration outliers makes them difficult to analyze, and a 1989 EPA report excluded them when calculating averages. The EPA values have been used as averages in a number of recent analyses, but in fact are close to the 50 th percentile (median) values, and about 2 to 4 times smaller than averages calculated from the distribution curves in the more recent EPRI report.

Table 2 lists summary information about the different fuels, and provides brief notes, which are amplified below, on how some of the values were derived. Values for the mean heat content of fuels, and the power plant heat rates are included.

The average coal and oil mercury concentrations were approximately $20 \%$ of the maximum concentrations, and this percentage was used to estimate a mercury concentration for natural gas. Up to $60 \%$ of the mercury in natural gas may initially get adsorbed in pipes and or lost in pumps, but eventually these "sinks" appear to saturate. In table 2 the adjusted concentration for mercury in natural gas is based on the assumption that $80 \%$ of the mercury arrives at the power plant. The final estimate is consistent with the lower range estimate for power plant emissions in Minnesota. Because of the uncertainty over the fate of mercury in pipelines, other estimates in the literature range from 200 times lower to 5 times higher than the estimate here. Although the uncertainties in the gas calculation are proportionally larger than for oil or coal, the larger base concentration and the larger fraction of power generated by the later makes their uncertainties more significant to the overall uncertainty of mercury emissions from power plants.

Power plants burn residual and distillate oils, which we have lumped under the heading fuel oil. Crude oil is separated into fractions by distillation, and the fuel oils represent some of the heavier, or less volatile fractions. Most trace metals tend to concentrate in these heavy fractions, but mercury is volatile, and concentrates instead in the lighter fractions.

Coals contain minerals when mined. These minerals are typically heavier than the actual coal. Raw coal can be "cleaned" by pulverizing it, and then mixing it with a fluid that floats the coal, and lets the minerals settle. Coal cleaning removes an estimate of $30 \%$ (range $0 \%$ to $70 \%$ ) of the mercury in coal. Adjusted coal concentrations use a factor of 0.88 to account for the $40 \%$ of coal in the U.S. that is currently cleaned.

The amount of mercury captured by air pollution control devices depends on combustion contitions and flue gas temperature. The mercury in the flue gases of waste combustors is 
present as $\mathrm{HgCl}_{2}$. $\mathrm{HgCl}_{2}$ condenses at flue gas temperatures, and forms particulates which are removed at up to $80 \%$ efficiency by standard particulate control devices. Power plant exhausts do not normally co; in appreciable chlorine. In an efficient plant the mercury in the flue gases is apparently mostly elemental mercury vapor, which is not captured by the particulate control equipment. A 1980 study of a 2600 MW TVA power plant found $92 \%$ of the feedstock mercury escaped the wiant as vapor, $7 \%$ escaped as particulate, and only $1 \%$ was collected in the plant as ash.

Although there are other studies showing no mercury control, it appears that on average $30 \%$ of coal-fired power plant mercury is removed by particulate control devices. Most gas and oil burning plants do not use particulate control. Mercury removal was best at low temperatures, and it has been suggested that the mercury was condensing. Calculation shows that condensation as mercury droplets is not possible for the conditions in the flue, but adsorption or surface reactions should be. These reactions should be more efficient at low temperatures. The deliberate introduction of activated carbon or coke in conjunction with particulate control devices has been shown to be up to 80 to 90 percent efficient at removing mercury from exhaust gases.

The adjusted mercury output values include only the mercury that is actually released to the atmosphere. The "raw" values include mercury that is landfilled, or disposed of elsewhere. We have assumed that this mercury is relatively immobile, and have not coisicered it further. The estimate does not include the mercury released from soils and vegatet on when land is inundated for reservoirs for hydropower. Mercury levels 2 to 5 times pieninundation levels have been found in reservoir fish five years after flooding. This problem is separate from the problems caused by mercury releases from combustion.

As noted earlier the average values in the table are approximately twice median levels. Values in the table are estimates for current emission levels. A shift to cleaner fuels could reduce mercury emissions by a factor of two. Control technologies based on activated carbon, sodium hypochlorite, sulfur impregnated alumina or carbon, and lignite-coke have been reported to be capable of capturing $\mathbf{8 0}$ to over $\mathbf{9 5 \%}$ of the mercury in the exhaust stream. Based on these claims it appears the future mercury emissions could be reduced by a factor of ten or more.

\section{Mercun from Lamps: from power use and lamp disposal}

Table 1 has already presented information on the amount of mercury in lamps. The values in table 1 do not include mercury losses in lamp manufacture, or the amount released by power generation. A check on the possible magnitude of manufacturing losses can be made by comparing larnp sale data and mercury purchase data for the lamp industry. The best leastsquares fit for the period from 1978 to 1987 suggests that it took $70 \mathrm{mg}$ of mercury to make the average fluorescent lamp, and $660 \mathrm{mg}$ of mercury to make the average HID. The fluorescent lamp estimate is consistent with estimates for lamp loading, and suggests losses in the range of 10 to $30 \%$. The HID estimate is ten times higher than current lamp loading estimates, and suggests data problems. The data for 1988 and 1989 shows drastically smaller mercury consumptions that are consistent with 10 to 20 percent losses for both fluorescents and HIDs. Dlata was not listed for 1990 or later. Given the present high visibility of mercury issues it seerns likely that current manufacturing losses can be assumed to be $10 \%$ or less and falling, and we therefore have not considered them further.

Table 3 displays the total mercury burden for most of the lamps in table 1, and for a number of incandescent lamps. Since different lamps have different lifetimes and light outputs the results are normalized by dividing by lamp lumen-hours, calculated is the lamp's rated lumen 
output times its rated life. The calculation for the indirect mercury burden due to power plant emissions is based on the estimated national weighted average of 54 nanogra.ns per watt-hour (ng/wh). The ranges in table 2 can be used to estimate how this value might vary in different locations.

In general, lower wattage lamps are less efficient, and usually have a higher mercury burden per lumen-hour than bigger lamps. All but one of the fluorescents, and all of the HIDs have a lower mercury burden than the reference 100 watt incu.ndescent lamp on a national basis. The last column in the table shows the por. or plant mercury emission rate that would be needed for the lamp to have the same total burden as the 100 watt incandescent lamp. Most HIDs will have a lower mercury burden than incandescents even if future power plant pollution equipment reduces mercury emissions by a factor of ten to $5.4 \mathrm{ng} / \mathrm{wh}$. Fluorescent lamp manufacture trends suggest that future lamps will be filled with about $1 / 3$ less mercury than at present. At a power plant rate of $5.4 \mathrm{ng} / \mathrm{wh}$, most fluorescents will have 1.5 to 2 times the mercury burden of a 100 watt incandescent.

\section{Erom lamp or power plant to aquatic mercury and methylmercury}

The values in table 3 are not corrected for the amount of mercury released that actually enters the biosphere and becomes a problem. Nor do they account for power plant emissions which affect the toxicity or bioavailability of mercury, or are toxic in their own right. Mercury in lamps that is landfilled, or even better recycled, appears to be less bioactive than that released by power plants, or waste combustion.

The adjusted mercury power plant emission rates in table 2 are for vapor and fine particulates. The rate at which particulates settle depends upon weather conditions such as rain, and ranges from hours to days. This makes particulate fall-out a local or regional phenomena. Mercury vapor removal also depends upon weather conditions and may take months or years. Dispersion is quickest for small sources, and is slow for plumes or area sources. Lindberg found a plume of mercury enriched air $22 \mathrm{~km}$ from a TVA power plant. Studies in Sweden, the northern U.S., and Canada have traced mercury problems in local areas to mercury contamination hundreds of kilometers away. Thus mercury vapor fallout extends from the regional to the global scale.

Mercury in fuels or ores below the earth's surface is inaccessible to the biocycle for geological times. Burning fuels makes the mercury almost immediately accessible, but not all of it actually gets into the biocycle. Perhaps $1 / 2$ of the mercury settles into the ocean, and is eventually removed to deep sediments. Limited sampling suggests that $5 \%$ of the net deposition on land ends up in ground water, and that perhaps $25 \%$ ends up in lakes or rivers from groundwater and run-off from the local catchment area. Since there are areas with no permanent lakes or rivers the overall transfer rate is probably about $10 \%$.

In remote lakes where atmospheric deposition appears to be the only source of mercury, studies of sediment core samples indicate that mercury concentrations have increased by almost four over the last two hundred years. Studies on preserved and fresh fish samples suggest a somewhat higher rate of increase than the core samples. This is possible because the amount of mercury that is converted to methylmercury and is accumulated by fish is partly dependent upon the acidity of the water, and can vary by a factor of ten over the range of acidities found in lakes. Power plants have been implicated in the acidification of lakes, although they also emit selenium, which binds to mercury and makes it less available. The fish and core samples suggest that acidification is the more important factor, and may even be as important as mercury deposition in some lakes. 
Used lamps are either recycled, or disposed of as solid waste, which is then either landfilled or incinerated. In 1992, only Minnesota and California appeared to be regulating lamp disposal, but a number of other states are looking at this option. These programs are still new, and currently only about two percent of used lamps are recycled, at a cost of about $55 \pitchfork$ per lamp. These two states have $13.7 \%$ of the U.S. population. Disposal by households and small businesses are not easily controlled, but only $20 \%$ of the fluorescent lamp sales are estimated to go to these users. The potential ior recycling for these two states alone is thus about $11 \%$.

The EPA estimates that approximately 14 percent of the solid waste stream is incinerated, and 13 percent is recycled. The later fraction generally involves paper, containers, and yard wastes that do not contain mercury. In Minnesota about 1/4 of the large waste incinerators separate out non-combustibles from the fuel. This leads to the following estimates for lamp recycling, incineration, and landfilling: $2 \%, 12 \%$, and $86 \%$ now, and $11 \%, 11 \%$, and $78 \%$ in the near future.

In June, 1992, EPA regulations prohibited mercury reclaimed from recycled lamps from going to a hazardous waste landfill, and the mercury now goes to a mercury recycler for reuse. It has been estimated that about $99 \%$ of the mercury can be reclaimed, and $0.8 \%$ of the mercury is disposed with the glass, metal and powder residue. Approximately $0.3 \%$ of the mercury is estimated to be lost as vapor, with most of it being lost from breakage in transit or storage. Mercury emissions from the generation of the power needed to reclaim mercury are approximately $0.003 \%$ as much mercury as is reclaimed, and can be ignored. The estimated worst case transfer rate of mercury to lakes and rivers from recycling lamps is $0.03 \% \quad(.003$ $x .1)$.

To calculate a transfer rate for incinerators we assume that the mercury escape rate from landfilled flue ash is negligible. Particulate control technologies are assumed to currently average $30 \%$ capture of input mercury. Particulate control for municipal waste combustors is similar to that of power plants, and future capture fractions are assumed to be $80 \%$. Mercury exhausts from incinerators appears to be predominately $\mathrm{HgCl}_{2}$ which will either be captured in the flue ash, or will settle out in local or regional areas near the incinerator. We therefore assume that $75 \%$ of the exhaust plume mercury settles on land or fresh water. The transfer of mercury from land to water is assumed to be the same as was calculated for power plants $(20 \%)$ so the overall transfer rate for lamp incineration is estimated to be $10 \%$ now, and $3 \%$ with advanced mercury control. These figures may underestimate the impact of an incinerator on a local lake or river.

Lamps destined for landfill can be expected to be either broken in transit or at the landfill. The EPA estimates from 3.4 to 8.4 percent of lamp mercury evaporates before the solid waste is covered at the landfill. However this estimate is based on a set of worst-case assumptions, such as no chemical reactions, absorption, or adsorption of the mercury, exposed surfaces, and saturation of the pore space of the waste. Under these assumptions the mercury evaporation rate is independent of the amount of mercury in the waste.

The EPA estimate assumes on average that the lamps are broken and exposed for an average of one day. Our lamp breakage scenarios lead to estimates of 0.5 to 2 percent mass loss over this period. Our estimates assume that the mercury is not mixed in with large amounts of other materials which tend to slow diffusion, and we therefore believe that they should be conservatively high. We therefore assume a one percent loss during transit and unloading, instead of the higher EPA estimates.

Once in the landfill, mercury can either vaporize into the atmosphere, leach out into ground water, remain as elemental mercury in situ, or react with other materials to form relatively 
immobile compounds such as HgS (cinnabar). Elemental Mercury can be surprisingly immobile when buried. Archaeologists excavating La Isabella in the Dominican Republic found elemental mercury in the soil that is thought to be waste from gold mining activities of the Spaniards almost 500 years earlier.

Studies of leachate over time appear to indicate that initial leachate concentrations decline by a factor of ten in slightly under a year, and then stabilize. Based on a simple exponential model this indicates that long term leachate rates will be $\mathbf{4 0}$ percent of the first year leachate rate. Leachate mercury concentrations for existing landfills have been estimated as $0.8 \mu \mathrm{g} / \mathrm{liter}$ value by the EPA, and $1.2 \mu \mathrm{g} /$ liter by Minnesota for its landfills. The EPA used their estimate and an estimate of leachate production for several landfills to estimate that on average $7 \times 10^{-6}$ of the annual input of mercury is lost to teachate, however this estimate assumes that mercury stops leaching after one year. If the landfills are assumed to be six years old, the above exponential model of leachate production leads to an initial rate estimate of $2.3 \times 10^{-6}$ of the mercury being leached the first year, and an addition $1 \times 10^{-6}$ being lost annually for some unknown duration thereafter. The Minnesota data gives leachate production as $40 \mathrm{liters} / \mathrm{m}^{2}$. year. Under the same assumptions as above this leads to the same fractional loss rates if the landfill is assumed to have an average density and mercury concentration, and is ten meters deep, which is in fact a typical depth. Leachate is typically sent to a waste water plant. Waste water plants capture about $65 \%$ of the mercury in the sewage sludge, so the total transfer fraction for leachate is about $3.5 \times 10^{-7}$ per year.

The above estimates are for modern capped and lined landfills, but older landfil's were not lined or capped, and this should result in higher quantities of possibly more dilute leachate. Since leachate production for the Minnesota landfills is about $1 / 16$ th of the rainfall for the region we have 16 times more volume in older landfills. We have arbitrarily assumed that the leachate mercury concentration is 0.5 that of modern landfills, and that $50 \%$ of the leachate reaches surface water. The resultant estimated long-term transfer fraction is $4 \times 10^{-6} /$ year.

Landfills produce methane and carbon dioxide, and these gases contain small concentrations of mercury. In capped landfills the methane is either deliberately vented, or captured for combustion. In the absence of specific data we have assumed that mercury vaporization rates are the same for both types of landfill. The estimated mercury concentration of landfill gases averages $400 \mathrm{ng} / \mathrm{m}^{3}$ from a Swiss study, while a Florida study quotes a value of $240 \mathrm{ng} / \mathrm{m}^{3}$. There does not seem to be good information on the quantity of landfill gases. Two EPA estimates of mercury fluxes (and hence landfill gas emissions) differ by a factor of 20 . Both EPA estimates assume gas emissions for a single year. A Florida estimate of the total potential gas emissions per metric ton of solid waste, $238 \mathrm{~m}^{3} / \mathrm{MT}$, leads to a lower gas emission than the higher of the EPA annual gas emission estimates. The mercury fraction emission estimates from these sources range from $2 \times 10^{-6 / y e a r}$ to $4 \times 10^{-5} / y e a r$.

An alternative method of estimating landfill emissions is from the atmospheric mercury concentration above the landfills. Mercury above Swedish landfills was measured at 10 to 25 $\mathrm{ng} / \mathrm{m}^{3}$, or possibly 10 to 20 times background levels. This ratio is close to the ratio of landfill mercury to soil mercury. Lindberg quotes a rate of $220 \mu \mathrm{g}$ per square meter for uncontaminated soils. For a ten meter deep area equivalent to a landfill this leads to an estimate of a transfer rate into the atmosphere of $1.5 \times 10^{-4} /$ year. Lower transfer rates have been found for soils and chlor-alkali waste disposal ponds. The discrepancy in the values suggest that not all the mercury is associated with methane and carbon dioxide production. For further calculations we have chosen to use the value $1.5 \times 10^{-4} /$ year as the most conservative estimate of environmental impacts. 
It is not proper to directly compare the slow releases of mercury from landfills with the prompt releases from combustion, or surface vaporization. Mercury from discarded lamps should continue to be vented or leached for many years after disposal of the lamps.

The residence time for mercury in landfills appears to be appreciably longer than the residence time for mercury in the biosphere. Ferguson estimates a four year residence time against loss to the atmosphere, but much of the atmospheric mercury should eventually cycle back to the biosphere. If $10 \%$ of the mercury is assumed to be lost to ocean sediments, then the overall biosphere residence time would be 40 years. The real number is probably smaller, but the important poini is that mercury released into the biosphere 100 years ago is not still present in the biosphere now, and therefore should not be counted with current releases.

We use the 40 year figure to compute a transfer factor for landfills as $0.16 \%(.1 \times[.01+40$ $\left.\left.x\left[1.5 \times 10^{-4}+3.5 \times 10^{-7}\right]\right]\right)$. This value is dominated by our estimate that $1 \%$ of the mercury is lost to the atmosphere before it reaches the landfill. The mercury lost to leachate, although possibly locally hazardous, is of such small quantity that it is not significant in the overall estimate.

In summary we estimate the amount of mercury transferred to the biocycle from power plants as $5.4 \mathrm{ng} / \mathrm{wh}$, with a potential reduction to $0.54 \mathrm{ng} / \mathrm{wh}$. Lamp disposal, weighted by the relative fractions of landfill, incineration and recycling is estimated to transfer $1.3 \%$, with a potential reduction to $0.46 \%(.86 \times .0016+.12 \times .1+.02 \times .0003=.013$, and $.78 \times .0016$ $+.11 \times .03+.11 \times .0003=.0046)$. The biologically available mercury from a 100 watt incandescent light is $0.31 \mathrm{ng} / \mathrm{lumen}$-hours now, with a potential reduction to 0.031 ng/umen-hours. For comparison the figures for the 5 watt fluorescent, which is the worst of the discharge lamps, are 0.19 and 0.029 ng/lumen-hours respectively. Figures for the F40T12 lamp show an even larger advantage over the incandescent lamp: 0.084 and 0.008 ng/lumen-hours.

These estimates should not be construed as indicating that lamp disposal is not a problem. Landfill leachate and run-off may cause local problems if they directly contaminate a small lake which has little ability to dilute the mercury. It should be remembered too that lamps are not the only source of mercury in landfill. If only lamps contained mercury the typical landfill would have $250 \mathrm{ppb}$ mercury, which is only 5 times the average crustal level. Actual landfill concentrations are more like $4,000 \mathrm{ppb}$, primarily because of batteries. This situation is changing, but its legacy will still be with us for many years.

\section{Discussion and Conclusion}

Is the amount of mercury in a lamp hazardous if it breaks? Mercury is toxic, and there have been numerous cases of occupational poisoning in the past. However, these cases involved far greater quantities of mercury than is present in the number of lamps found in a typical office, and the risks appear low.

Should one use incandescent lamps instead of fluorescents because of the hazards of mercury in the environment? Unfortunately, fossil fuel fired power plants release mercury as an unwanted by-product of producing electricity. The evidence that we have presented shows that the indirect release of mercury from power generation for an incandescent lamp will normally be larger than the direct and indirect releases for fluorescent or HID lamps. In addition, although estimates of bioavailability are necessarily speculative, it appears that mercury in power plant exhaust gases is substantially more bioavailable than recycled or landfill mercury. 
There may be local exceptions to this rule from incineration of mercury bearing wastes, or leachate or run-off into nearby lakes or rivers. Nuclear power electricity generation also leads to a local exception, but it should be obvious that nuclear power has waste problems of its own that may equal those from the mercury releases from lamp disposal. The generation of electricity by hydropower does not release mercury. However, filling the reservoirs created to provide the water for a hydropower plant can cause local mercury problems. Based on the limited data we have presented the balance again appears to favor fluorescent lamps. We have not analyzed wind and solar power, but these sources of electricity are so small that the amount of mercury from the lighting that they power is likely to be insignificant.

\section{Acknowledgement}

This work was supported by the Assistant Secretary for Energy Efficiency and Renewable Energy, Office of Building Technologies, Building Equipment Division of the U.S. Department of Energy under Contract No. DE-AC03-7655F00098.

\section{References}

[1] L. Goldfrank et. al. "Mercury". In Clinical Toxicology. Thienes, C. and Hanley, T. eds. Lea and Febiger, Philadelphia.

[2] World Health Organization. 1991. Environmental Health Criteria 118. Inorganic Mercury. Geneva.

[3] Environmental Protection Agency. 1984. Mercury Health Effects Update. Health Issue Assessment. EPA-600/8-84-019F

[4] HEW. 1973. Criteria for a recommended standard ... Occupational Exposure to Inorganic Mercuny U.S. Dept. of Health, Education and Welfare

[5] Browning, E. 1961. Ioxicity of Industrial Metals. Butterworths, London.

[6] W. Tunnessen, et. al.. 1987. "Acrodynia: Exposure to Mercury From Fluorescent Light Bulbs". Pediatrics, Vol. 79(5), pps 786 - 789.

[7] Adler, R., et. al.. 1982. "Metallic mercury vapor poisoning simulating mucocutaneous lymph node syndrome". The Journal of Pediatrics. Vol.101(6). pps 967 - 968.

[8] Truesdale, R., Beaulieu, S. and Pierson, T. 1992. Management of Used Fluorescent Lamps: Preliminary Risk Assessment. Research Triangle Institute Project No. 94U5400-010. Submitted to David Layland, USEPA, Office of Solid Waste, Characterization and Assessment Division, Washington, DC.

[9] Phone conversations with A. M. Zielinski, GE, and Peter Bleasby, Osram.

[10] Walitsky, H. and Bleasby, P. 1992. "Classification and Disposal of Lamps Containing Mercury: Tackling the Issue". Lighting Management and Maintenance. pps $10-11$.

[11] NEMA summary sheet, circa 1991: "Current Range of Selected Substances of Representative Lamp Types". 
[12] Form letters from A. M. Zielinski, GE: 216-266-3349.

[13] Cayless M. and Marsden A., eds. 1983. Lamps_and Lighting. Edward Arnold, Baltimore.

[1 4] Waymouth, J. 1971. Electric Discharge Lamps, MIT Press. Cambridge, Mass.

[15] Jost. 1960. Diffusion in Solids_Liquids. Gases. Academic Press, New York.

[16] Geological Survey Professional Paper 713, 1970. Mercury in the Environment. U.S. Govt. Printing Office, Washington.

[17] Iverfeld, A., and Lindqvist, 0 . 1986. "Atmospheric Oxidation of Elemental Mercury by Ozone in the Aqueous Phase". Atmospheric Environment. Vol. 20(8): 1567 . 1573.

[18] Ferguson, J. 1990. The Heavy Elements: Chemistry. Environmental Impact and Health Effects. Pergammon Press. New York.

[19] Hart, B. T. 1982. Australian water quality criteria for heavy metals. Australian Water Resources Council, Technical Paper No. 77. Australian Government Printing Services, Canberra, Australia.

[20] Cole, H., Hitchcock, A., and Collins, R. 1992. "Mercury Warning: The Fish you Catch may be Unsafe to Eat". Clean Water Fund/Clean Water Action. 1320 18th Street, NW., Washington, DC 20036.

[21] Rauber, P. 1992. "Mercury Madness". Sierra, Vol. 78(1): 36 - 39.

[22] Skerfving, S. 1988. "Mercury in Women Exposed to Methylmercury through Fish Consumption, and in their Newborn Babies and Breast Milk". Bull. Environ. Contam. Toxicol. Vol. $41: 475-482$.

[23] Olafsson, J. 1983. "Mercury Concentration in the North Atlantic in Relation to Cadmium, Aluminum and Oceanographic Parameters", in Irace Metals in Sea Water. Wong et. al. Ed. Plenum Press, NY, Pages 475 - 485

[24] Krishna Murti, C. R. 1987. "The Cycling of Arsenic, Cadmium, Lead and Mercury in India", in Lead. Mercury. Cadmium and Arsenic in the Environment. SCOPE 31. Hutchinson and Meema, Eds. Wiley and Son: Chapter 19, pages 315 - 334

[25] Neme, C. 1991. Electric Utilities and Lono-Range Transport of Mercury and Other Ioxic Air Pollutants. Center for Clean Air Policy, Washington, D. C.

[26] Porcella, D. 1990. "Mercury in the Environment". EPRI. Journal. April/May 1990. pages $46-49$.

[27] Bruland, K. 1983. "Trace Elements in Sea-Water", in Chemical Oceanography Vol. 8. Academic Press, London. Pages $157-220$

[2 8] Minnesota Pollution Control Agency. 1991. Leachate Disposal and Treatment Ontions. MPCA, 520 Lafayette Road, St. Paul, MN 55155. 
[29] Energy Information Administration. 1991. Annual Eneroy Review 1991. DOE/EIA 0384(91), Washington, D.C.

[30] Smith I. et. al. 1975. "Metals in New and Used Petroleum Products and ByProducts: Quantities and Consequences", in The Bole of Trace Metals in Petroleum. Yen, T. ed, Ann Arbor Press

[31] Pacyna J. 1986. "Emission Factors of Atmospheric Elements", in Toxic Metals in the Atmosphere. Nriagu, J., and Davidson, C., eds. Wiley \& Sons, New York.

[32] Bingham, M. 1990. "Field Detection and Implications of Mercury in Natural Gas". SPE Production Engineering. May 1990. pages $120-124$.

[33] Radian Corporation. 1989. Estimating Air Toxics Emissions From Coal and Oil Combustion Sources. EPA-450/2-89-001

[34] Chow, W. et. al. 1991. "Air Toxics \& the 1990 Clean Air Act: Managing Trace Element Emissions". Presented at sth Particulate Control Symposium. EPRI, Palo Alto, CA.

[3 5] Begley K. and Linderson, T. 1991. "Management of Mercury in Lighting Products", in Proceedings 1st European Conference on Energy Efficient Lighting: Right Light Bright Light. May 29-30, 1991. Stockholm, Sweden. Pages (397 - 410.

[36] 1956. Handbook of Chemistry and Physics. Chemical Rubber Publishing Company. Cleveland.

[37] 1989. Statistical Abstract of the United States. Bureau of the Census. Washington D.C.

[3 8] White, D., and Jackson, A. 1992. Technical Work Paper on Mercury Emissions from Waste Cembustors. Minnesota Pollution Control Agency, 520 Lafayette Road, St. Paul, Minnesota, 55155.

[39] KBN Engineering and Applied Sciences, Inc. 1992. Mercury Emissions to the Atmesphere in Florida. Final Repert. Prepared for Florida Department of Environmental Regulation, 2600 Blair Stone Road, Tallahassee, Florida, 32399.

[40] Kuhn, J., et. al. 1980. Abundance of Trace and Minor Elements in Oraanic and Mineral Fractions of Coal. Illinois Institute of Natural Resources, State Geological Survey Division, Urbana, Illinois. Environmental Geology Notes 88.

[41] Lindberg, S. 1986. "Mercury Vapor in the Atmosphere: Three Case Studies on Emission, Deposition, and Plant Uptake", in Toxic Metals in the Atmosphere. Nriagu, J. and Davidson, C. eds. Wiley \& Sons, New York.

[42] Lindberg, S. 1987. "Emission and Deposition of Atmospheric Mercury Vapor", in Lead. Mercury, Cadmium. and Arsenic in the Environment. Hutchinson, T. and Meema, K. eds. Wiley and Sons, New York.

[43] Makansi, J. 1992. "The Next Generation of Powerplants. Activated coke emerges as cleaning agent for stack gas". Power, August 1992, pps $80-82$. 
[44] Stokes, P. and Wren C. 1987. "Bioaccumulation of Mercury by Aquatic Biota in Hydroelectric Reservoirs: A Review and Consideration of Mechanisms", in Lead. Mercury. Cadmium and Arsenic in the Environment. SCOPE 31. Hutchinson and Meema, Eds. Wiley and Son: Chapter 19, pages 255 - 278.

[45] U.S. EPA. 1992. Characterization of Products Containing Mercury in Municipal Solid Waste in the United States. 1970 to 2000. EPA530-R-92-013, NTIS\# PB92-162 569.

[46] Swain, E., and Helwig, D. 1989. "Mercury in Fish from Northeastern Minnesota Lakes: Historical Trends, Environmental Correlates, and Potential Sources". Journal of the Minnesota Academy of Science. Vol. 55(1): $103-109$.

[47] Krabbenhoft, D., and Babiarz, C. 1992. "The Role of Groundwater Transport in Aquatic Mercury Cycling". Water Resources Research, . Vol. 28(12): 3119 - 3128.

[4 8] Swain, E., et. al. 1992. "Increasing Rates of Atmospheric Mercury Deposition in Midcontinental North America". Science, Vol. 257, August 7, 1992: pps 784 - 787.

[4 9] EPA. 1992. "Lighting Upgrade Waste Disposal". U.S. EPA Green Lights Program. February, 1992.

[50] Blake, N. 1992. "Public Utility Commissions Promote DSM Programs". Lighting Management \& Maintenance. October 1992. pps 8 -9.

[51] Walitsky, P. 1992. "Environmental Protection Agency Puts Lamps in the Spotlight". Lighting Management \& Maintenance. October 1992, pps 10 - 11

[52] Walitsky P. and Bleasby, P. 1992. "Classification and Disposal of Lamps Containing Mercury: Tackling the Issue". Lighting Management \& Maintenance. August 1992: pps $10-11$.

[53] Watson, T. 1992. "Fluorescent Lamps - A Bright New Recyclable". Resource Recycling. March 1992. pps $71-78$.

[5 4 ] Moore, E. 1993. Report on the Management of Mercurv-Containina Lamos. Minnesota Office of Waste Management, 1350 Energy Lane, St. Paul, MN 55108.

[55] EPA. 1990. Characterization of Municipal Solid Waste in the United States: 1990 Update, EPA/530-SW-90-042.

[56] Lyon, E. and Sacha, R. 1992. "Search for Columbus". National Geographic, Vol 182(1): $44-45$. 


\section{Table 1: Mercury in Lamps}

Lamp Type
Fluorescent
5 watt compact
9 watt compact
13 watt compact
18 watt compact
F32T8
F40T12
F96T12 - 800 ma

NEMA averages

F40T12 - 1985

F40T12 - 1991

F40T12 - 1995 projected

Mercury Vapor

75 watt

175 watt

250 watt

400 watt

1000 watt

Metal Halide

175 watt

400 watt

1000 watt

HPS

50 watt

400 watt

1000 watt
Hg Load (mg)

Low High

$\begin{array}{ccc}5 & 10 & 7.5 \\ 5 & 10 & 7.5 \\ 5 & 10 & 7.5 \\ 6 & 12 & 9 \\ & & 30 \\ 15 & 70 & 41 \\ 75 & 100 & 87.5\end{array}$

48

41

27

44

System watts Lumens

(estimate)

(rated)

$\begin{array}{cc}7 & 250 \\ 11 & 600 \\ 15 & 900 \\ 21 & 120 \\ 31 & 2850 \\ 44 & 3200 \\ 120 & 8900\end{array}$

1.071

0.682

0.500

0.429

0.968

0.932

0.729

3200
8900

$48 \quad 3200$

3200

1.000

0.932

0.750

12.81

8.44

$\begin{array}{cc}95 & 2800 \\ 210 & 7200 \\ 295 & 9800 \\ 455 & 17500 \\ 1085 & 40000\end{array}$

0.211

0.124

0.122

0.166

0.230

7.14

26

75.5

250

55

$\begin{array}{cc} & 30 \\ 63 & 59 \\ & 250\end{array}$

20

188

8.3

23

25

$\begin{array}{cc}215 & 15000 \\ 455 & 40000 \\ 1085 & 115000\end{array}$

0.140

0.130

0.230

2.00

$1085 \quad 115000$

$\begin{array}{cc}60 & 4000 \\ 465 & 50000 \\ 1075 & 140000\end{array}$

0.138

2.08

0.049

0.023

0.46

0.18 


\section{Table 2: Summary Table for Mercury in fuels}

\begin{tabular}{|c|c|c|c|c|c|c|c|c|c|c|}
\hline \multirow[t]{3}{*}{ Fuel } & \multicolumn{4}{|c|}{ Mercury Concentration (ppm) } & \multirow{3}{*}{$\begin{array}{l}\text { Heat content } \\
\text { BTU/kg }\end{array}$} & \multirow{3}{*}{$\begin{array}{l}\text { Heat rate } \\
\text { BTU/kwh }\end{array}$} & \multirow[t]{3}{*}{ Wh/kg } & \multirow{2}{*}{\multicolumn{2}{|c|}{$\begin{array}{l}\text { Mercury Output (ng/wh) } \\
\text { (From averages) }\end{array}$}} & \multirow{3}{*}{$\begin{array}{r}\text { Percent U.S. } \\
\text { electricity } \\
\text { generation }\end{array}$} \\
\hline & \multicolumn{3}{|c|}{ Percentiles } & \multirow[t]{2}{*}{ Average } & & & & & & \\
\hline & 10 & 50 & 90 & & & & & Raw & Adjusted & \\
\hline Coals (all) & 0.064 & 0.177 & 0.808 & 0.342 & 25834 & 10375 & 2313 & 148 & 91 & 55.6 \\
\hline Bituminous & 0.070 & 0.190 & 1.000 & 0.409 & 28800 & 10375 & 2580 & 160 & 99 & 37.6 \\
\hline Sub-bituminous & 0.035 & 0.125 & 0.320 & 0.168 & 21040 & 10375 & 1880 & 90 & 55 & 13.2 \\
\hline Lignite & 0.095 & 0.220 & 0.650 & 0.295 & 15850 & 10375 & 1420 & 210 & 129 & 4.8 \\
\hline \multicolumn{11}{|l|}{ Oil } \\
\hline Crude & & & & 4.975 & & & & & & \\
\hline Fuel Oil & 0.007 & 0.080 & 0.800 & 0.254 & 42200 & 10655 & 3660 & 69 & 69 & 4.2 \\
\hline Natural Gas & & & & 0.060 & 52760 & 10775 & 4900 & 12 & 10 & 9.4 \\
\hline Average & & & & & & & & 86 & 54 & 69.2 \\
\hline
\end{tabular}

Notes:

Values in italics are based on extrapolations or "educated guesses".

Values in bold represent the overall percentage for the fuel category.

Mercury concentrations: The percentiles and most of the averages are estimated from figure 4 of reference 33.

The crude oil value is the average of those reported in references $30 \& 32$.

The natural gas average is 0.2 times the maximum value quoted in reference 31 .

BTU/kg fuel: Coal values are from reference 32, fue! oil and gas values are from reference 35.

Reference 32 gives the following values for residual \& distillate oils: $41,930, \& 44,050$.

Heat Rates are from reference 36.

Wh/kg (watt-hours/kilogram): Transmission losses were assumed to be $7.2 \%$.

Mercury output - adjustments: raw coal values are multiplied by 0.88 for cleaning \& 0.7 for control equipment.

Raw gas values are multiplied by 0.8 to account for adsorption \& reaction in pipes \& pumping stations.

Percent Generation: Bold values from reference 28 - data for 1990.

Average mercury output assumes no mercury from nuclear, hydro, or other. 
Table 3: Total Mercury Burden - Direct \& from Power Consumption

\begin{tabular}{|c|c|c|c|c|c|c|c|c|}
\hline \multirow[t]{2}{*}{ Lamp Type } & \multirow{2}{*}{$\begin{array}{l}\text { Mercury } \\
\text { mg/lamp }\end{array}$} & \multirow{2}{*}{$\begin{array}{l}\text { Lifetime } \\
\text { (hours) }\end{array}$} & \multirow{2}{*}{$\begin{array}{l}\text { System watts } \\
\text { (estimate) }\end{array}$} & \multirow{2}{*}{$\begin{array}{l}\text { Lumens } \\
\text { (rated) }\end{array}$} & \multicolumn{3}{|c|}{ Mercury/lamp (ng/umen-hours) } & \multirow{2}{*}{$\begin{array}{c}\text { To match ref } \\
n g / w h\end{array}$} \\
\hline & & & & & Lamp & Power & Total & \\
\hline \multicolumn{9}{|l|}{ Fluorescent } \\
\hline 5 watt compact & 7.5 & 10000 & 7 & 250 & 3.00 & 1.52 & 4.52 & 102.9 \\
\hline 13 watt compact & 7.5 & 10000 & 15 & 900 & 0.83 & 0.91 & 1.74 & 20.6 \\
\hline 18 watt compact & 9 & 10000 & 21 & 1200 & 0.75 & 0.95 & 1.70 & 18.9 \\
\hline F32T8 & 30 & 20000 & 31 & 2850 & 0.53 & 0.59 & 1.12 & 11.4 \\
\hline F40T12 - 1991 & 41 & 20000 & 44 & 3200 & 0.64 & 0.75 & 1.39 & 14.8 \\
\hline F40T12 - 1995 & 27 & 20000 & 36 & 3200 & 0.42 & 0.61 & 1.03 & 9.2 \\
\hline F96T12 - $800 \mathrm{ma}$ & 87.5 & 12000 & 120 & 8900 & 0.82 & 0.73 & 1.55 & 18.8 \\
\hline \multicolumn{9}{|l|}{ Mercury Vapor } \\
\hline 175 watt & 26 & 24000 & 210 & 7200 & 0.15 & 1.59 & 1.74 & 5.4 \\
\hline 400 watt & 75.5 & 24000 & 455 & 17500 & 0.18 & 1.42 & 1.60 & 5.8 \\
\hline 1000 watt & 250 & 24000 & 1085 & 40000 & 0.26 & 1.48 & 1.74 & 8.7 \\
\hline \multicolumn{9}{|l|}{ Metal Halide } \\
\hline 175 watt & 30 & 10000 & 215 & 15000 & 0.20 & 0.78 & 0.98 & 4.7 \\
\hline 400 watt & 59 & 20000 & 455 & 40000 & 0.07 & 0.62 & 0.69 & 1.6 \\
\hline 1000 watt & 250 & 12000 & 1085 & 115000 & 0.18 & 0.51 & 0.69 & 3.8 \\
\hline \multicolumn{9}{|l|}{ HPS } \\
\hline 50 watt & 8.3 & 24000 & 60 & 4000 & 0.09 & 0.82 & 0.90 & 2.1 \\
\hline 400 watt & 23 & 24000 & 465 & 50000 & 0.02 & 0.51 & 0.53 & 0.4 \\
\hline 1000 watt & 25 & 24000 & 1075 & 140000 & 0.01 & 0.42 & 0.43 & 0.2 \\
\hline \multicolumn{9}{|l|}{ Incandescent } \\
\hline 60 watt & 0 & 1000 & 60 & 870 & 0.00 & 3.75 & 3.75 & \\
\hline 100 watt & 0 & 750 & 100 & 1750 & 0.00 & 3.11 & 3.11 & Reference \\
\hline 100 long life & 0 & 2500 & 100 & 1440 & 0.00 & 3.78 & 3.73 & \\
\hline 100-Halogen & 0 & 2250 & 100 & 1880 & 0.00 & 2.90 & 2.90 & \\
\hline
\end{tabular}

Note: The last column shows the power plant mercury that makes total lamp mercury the same as the 100 watt incandescent 
Figure 1: Concentration of $\mathrm{Hg}$ in air in grams per cubic meter

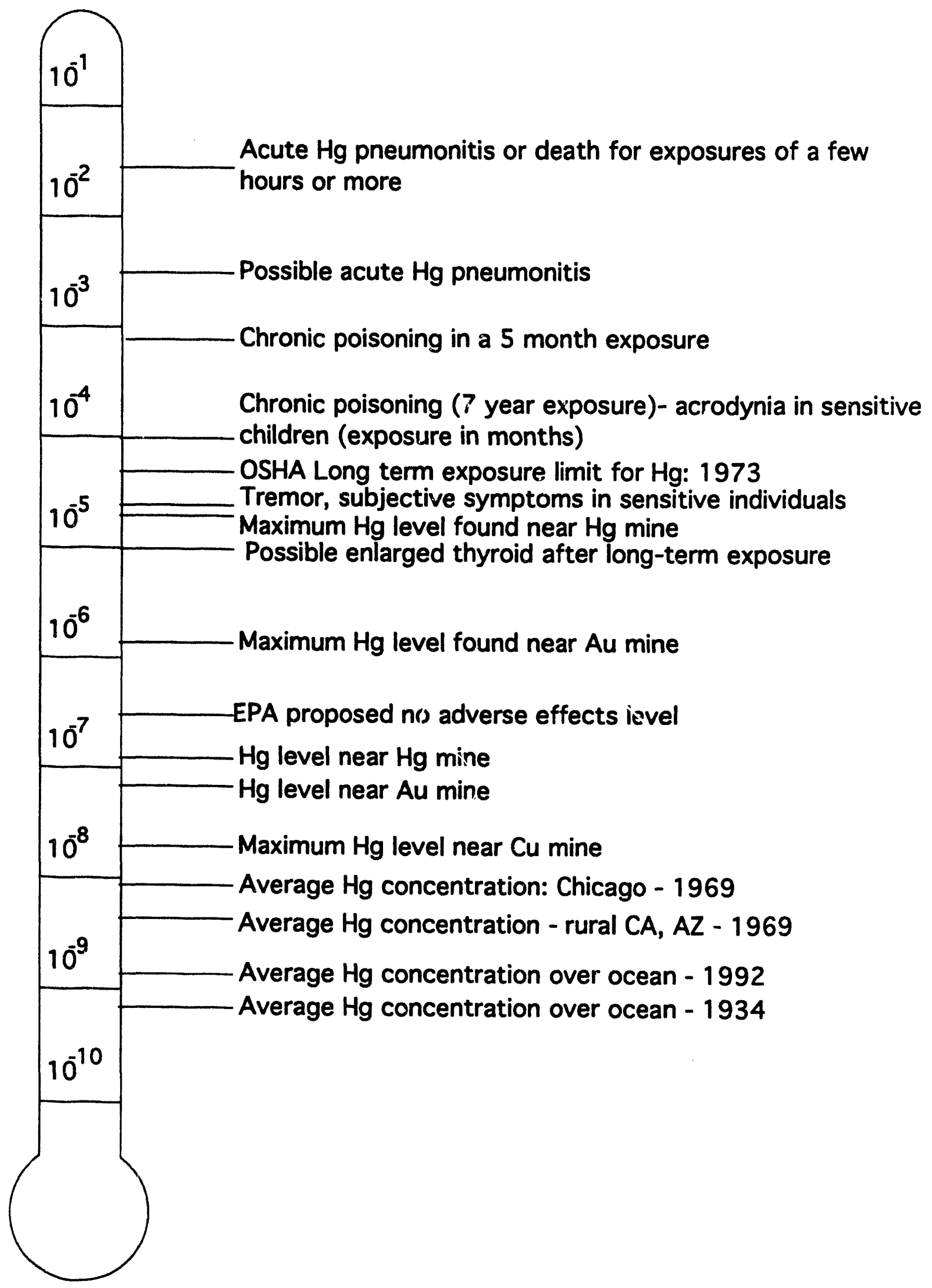


Figure 2: Mercury Air concentration $\left(\mu \mathrm{g} / \mathrm{m}^{\wedge} 3\right)$

versus time after lamp breakage (days)

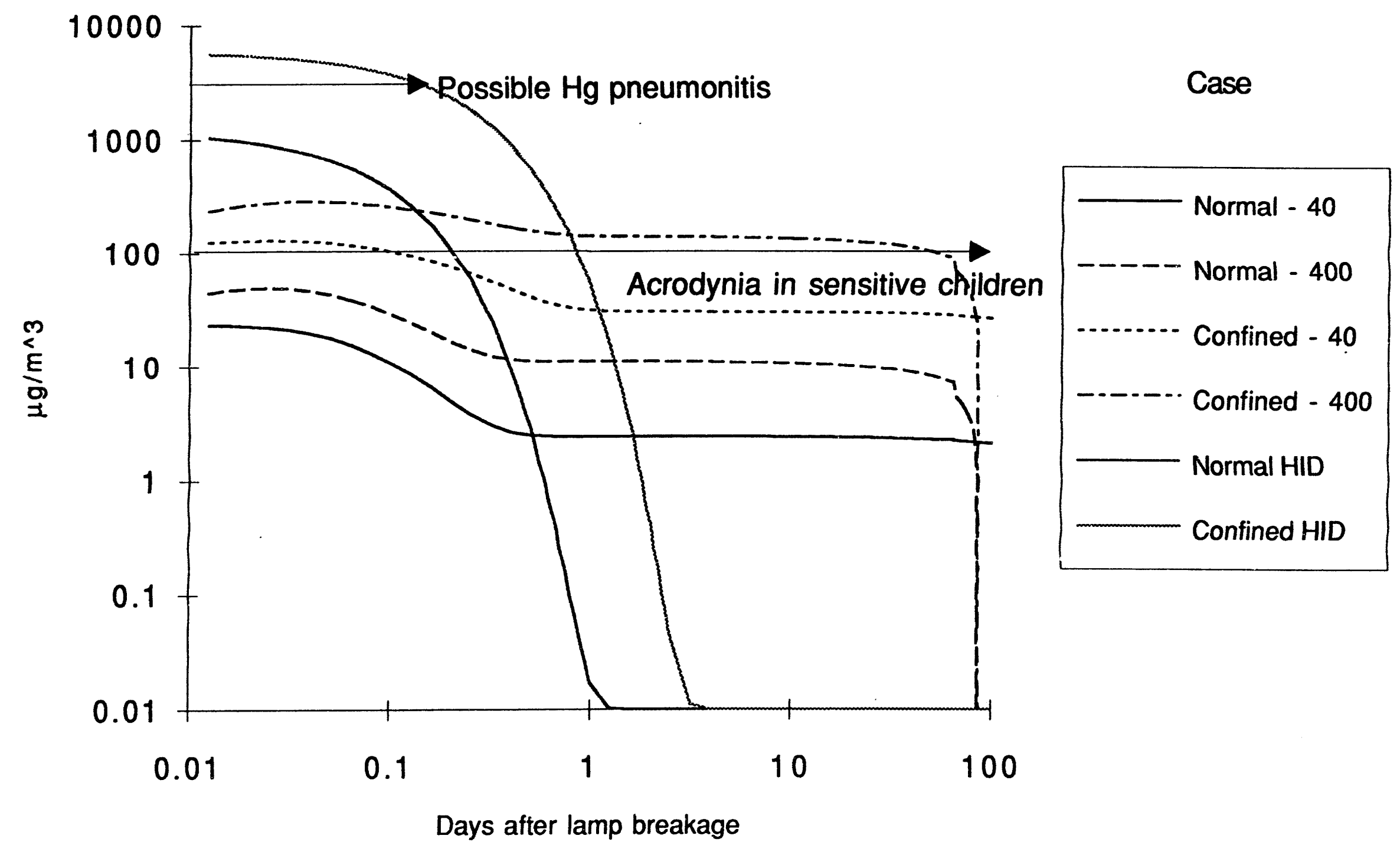


Figure 3: Concentration of $\mathrm{Hg}$ in water or sediment in grams per liter (kilogram)

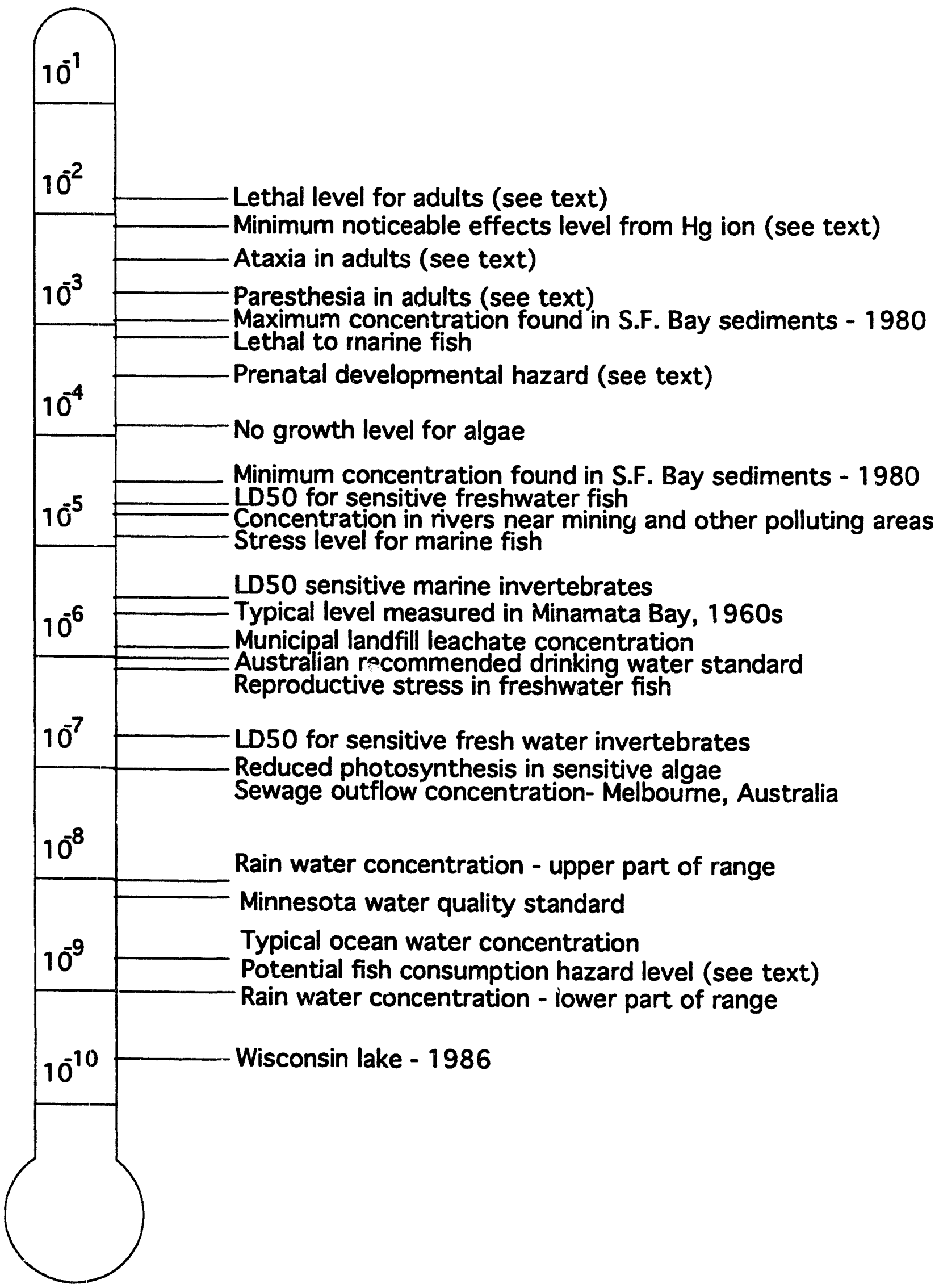


Figure 4: Concentration of $\mathrm{Hg}$ in food in grams per gram

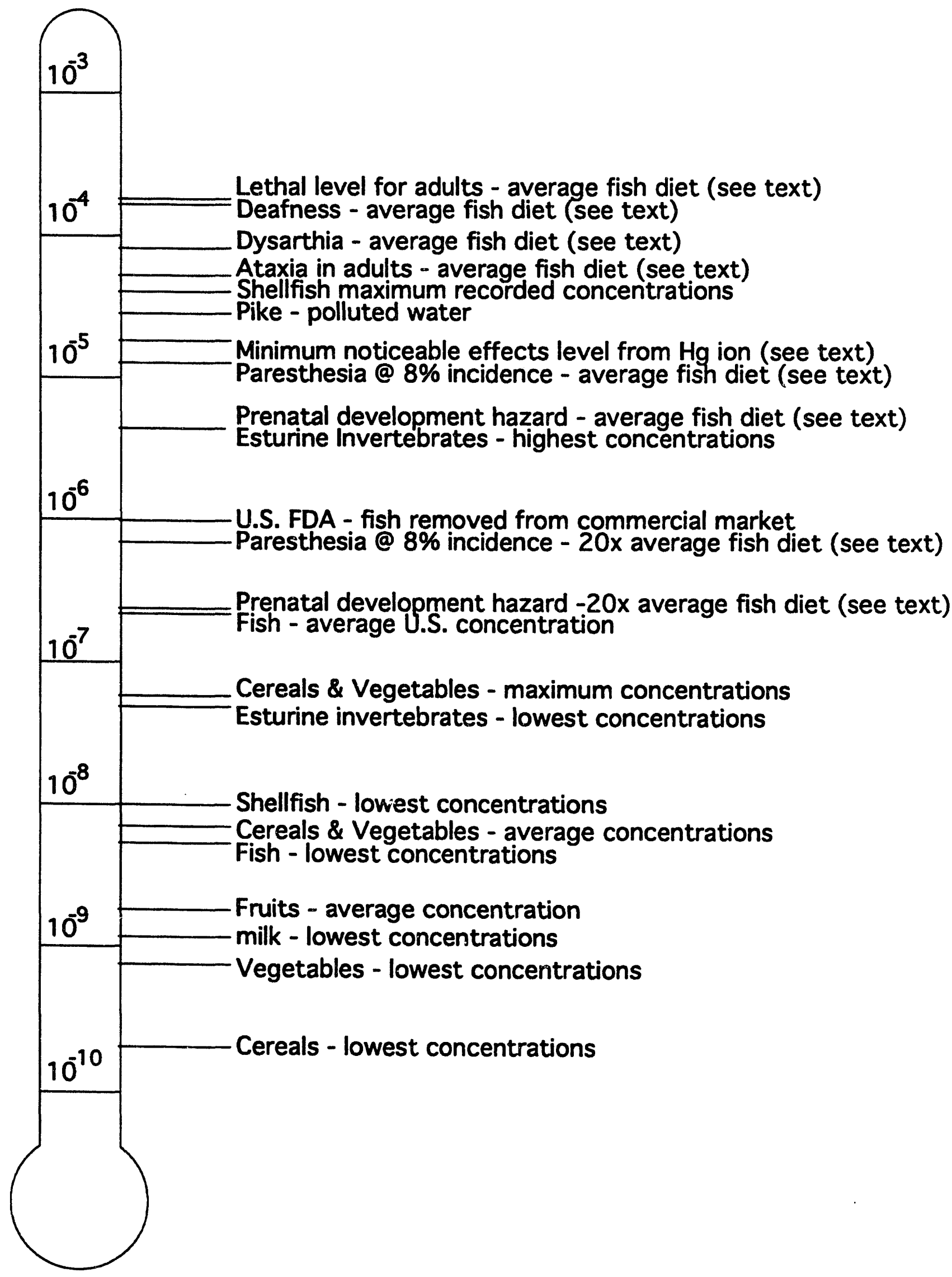


Figure 5: Percentage contribution to electricity generation versus time

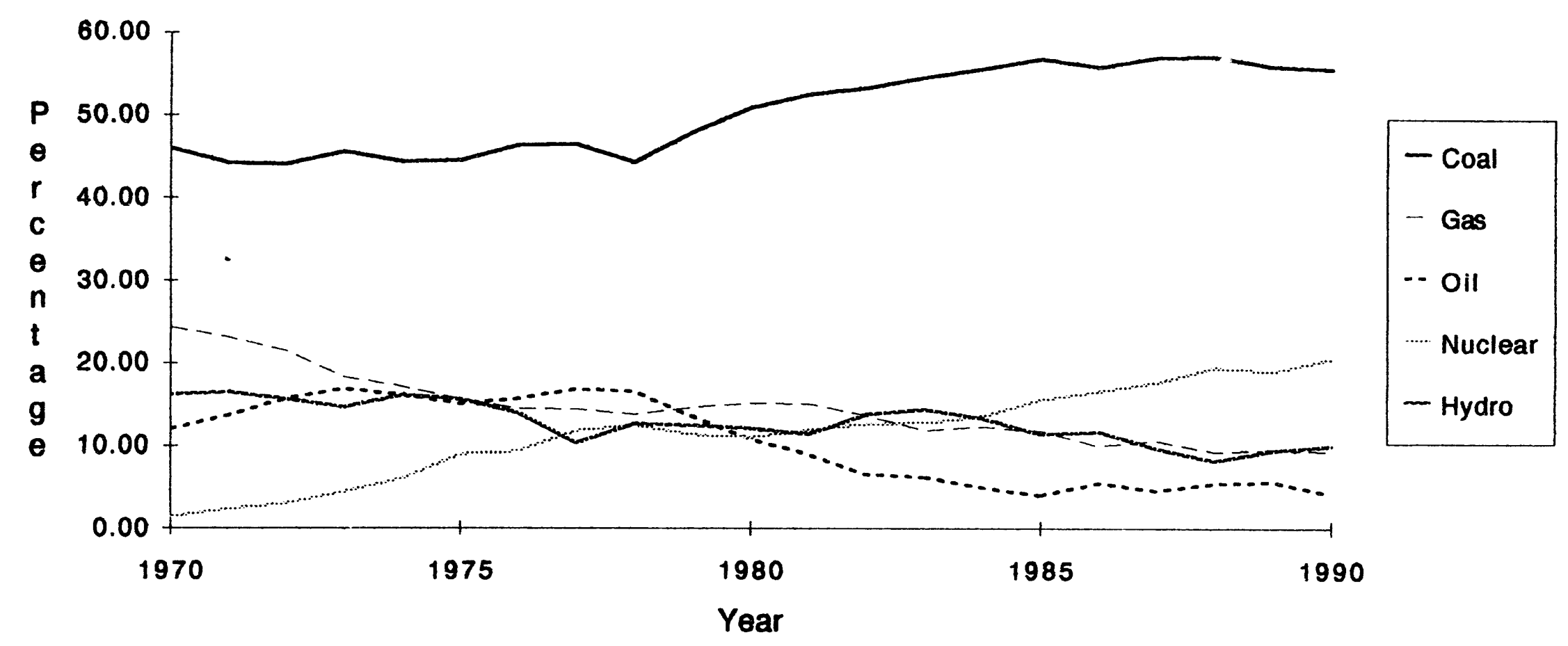


Figure 6: Probability distribution for mercury in Bituminous Coal

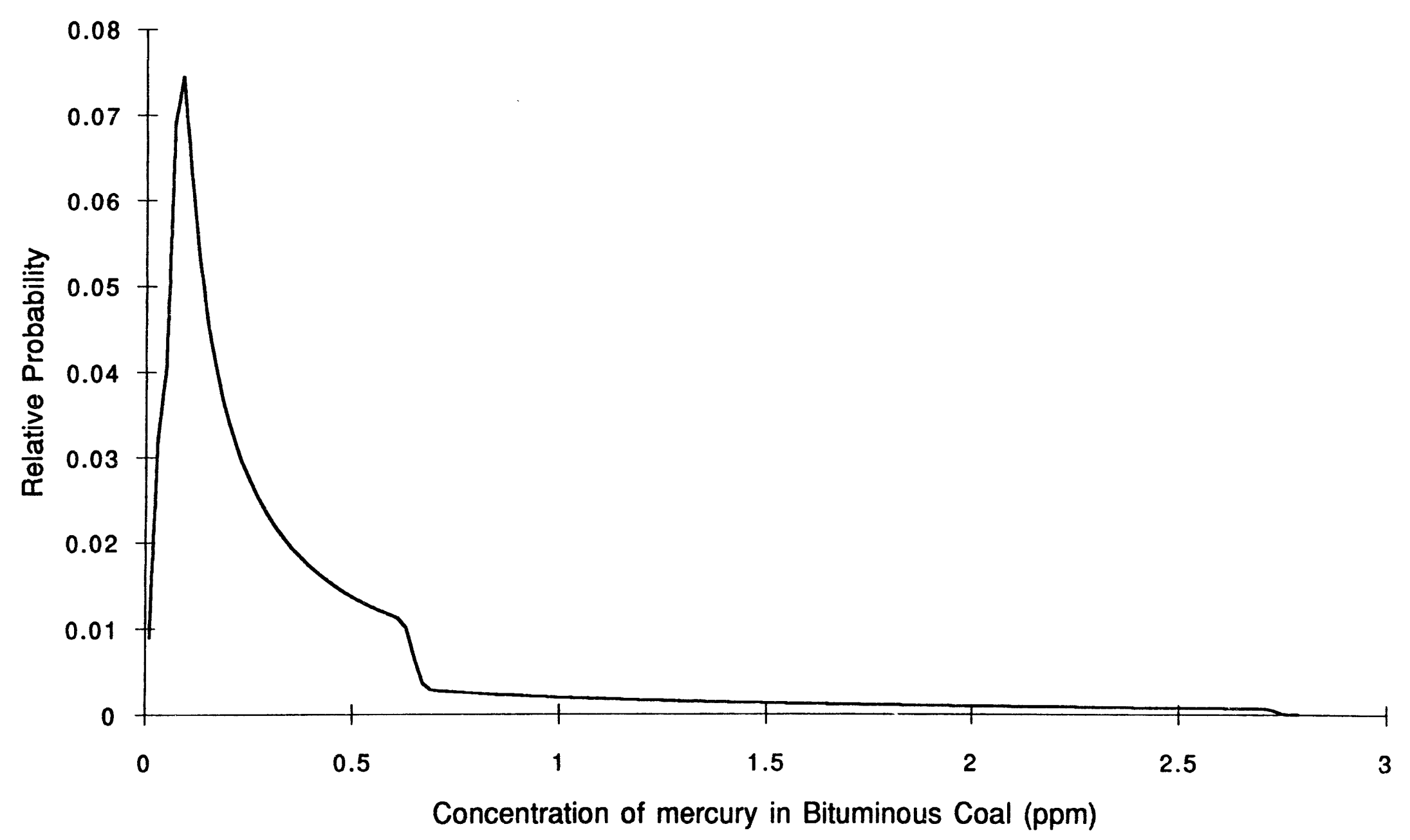



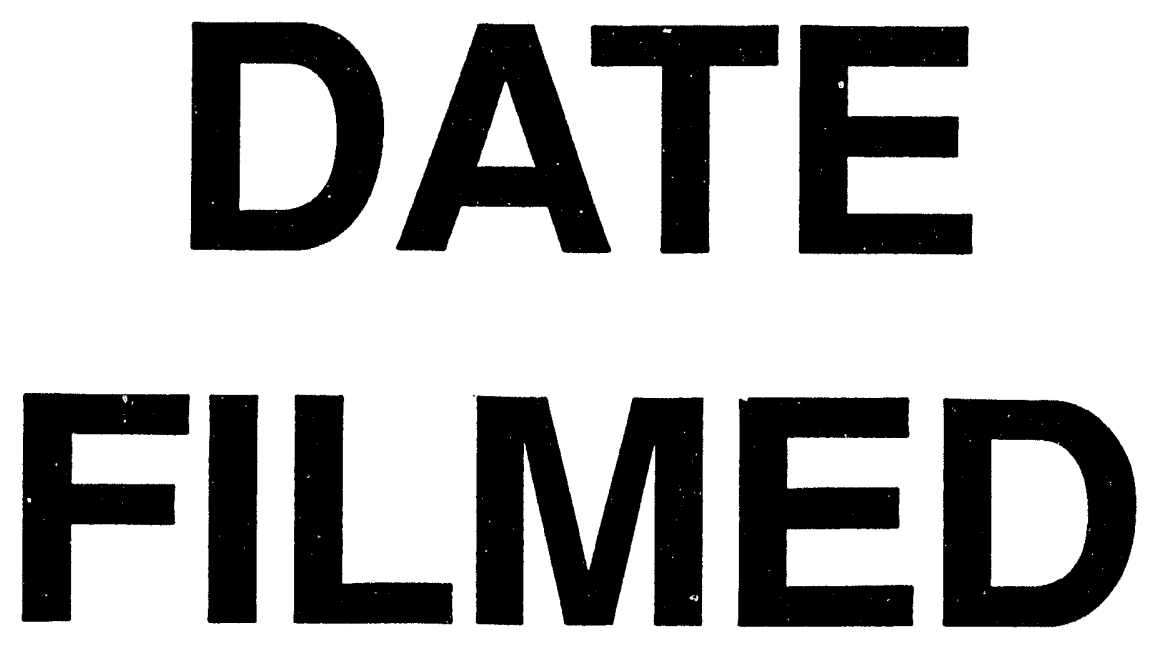

$10 / 20 / 94$
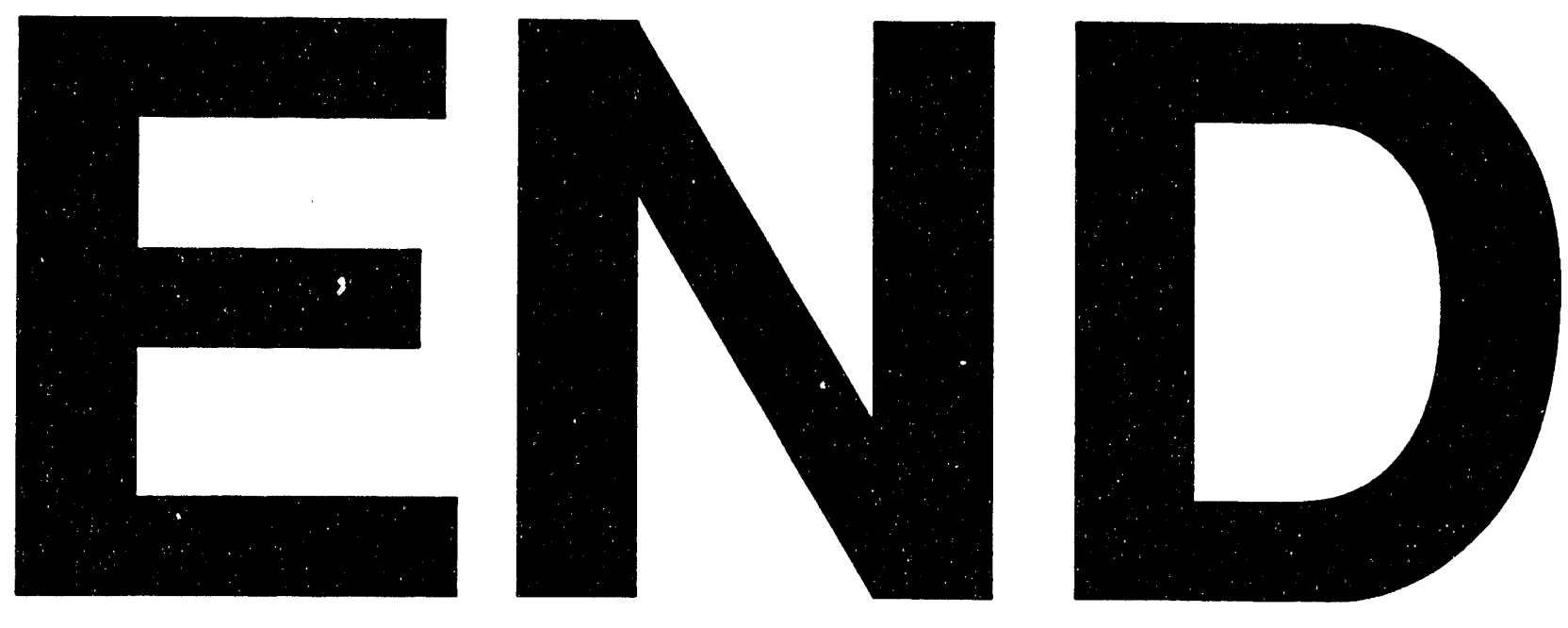
